NBER WORKING PAPER SERIES

\title{
EVALUATING LABOR MARKET REFORMS: A GENERAL EQUILIBRIUM APPROACH
}

\author{
César Alonso-Borrego \\ Jesús Fernández-Villaverde \\ José E. Galdón-Sánchez \\ Working Paper 11519 \\ http://www.nber.org/papers/w11519
NATIONAL BUREAU OF ECONOMIC RESEARCH
1050 Massachusetts Avenue
Cambridge, MA 02138
July 2005

We thank Samuel Bentolila, Maia Güell, Christian Hellwig, Pedro Mira, Juan Francisco Jimeno, Marcelo Veracierto, two referees, the editor, and participants at different seminars for helpful comments and discussions. César Alonso-Borrego thank the Spanish DGI for research funding, Grant BEC 2003-03943. Jesús Fernández-Villaverde thanks the National Science Foundation for financial support for Grant 0338997 and the Spanish Ministerio de Ciencia y Tecnología for financial support for project BEC2002-00954. José E. Galdón-Sánchez thanks the Spanish Ministerio de Ciencia y Tecnología for financial support for project BEC2002-00954, the Spanish Ministerio de Educación, Cultura y Deporte for project PR2003-0158, and the European Commission for a TMR Marie Curie fellowship. The views expressed herein are those of the author(s) and do not necessarily reflect the views of the National Bureau of Economic Research.

@ 2005 by César Alonso-Borrego, Jesús Fernández-Villaverde and José E. Galdón-Sánchez. All rights reserved. Short sections of text, not to exceed two paragraphs, may be quoted without explicit permission provided that full credit, including $\odot$ notice, is given to the source. 
Evaluating Labor Market Reforms: A General Equilibrium Approach

César Alonso-Borrego, Jesús Fernández-Villaverde and José E. Galdón-Sánchez

NBER Working Paper No. 11519

July 2005

JEL No. E24, C68, J30

\section{$\underline{\text { ABSTRACT }}$}

Job security provisions are commonly invoked to explain the high and persistent European unemployment rates. This belief has led several countries to reform their labor markets and liberalize the use of fixed-term contracts. Despite how common such contracts have become after deregulation, there is a lack of quantitative analysis of their impact on the economy. To fill this gap, we build a general equilibrium model with heterogeneous agents and firing costs in the tradition of Hopenhayn and Rogerson (1993). We calibrate our model to Spanish data, choosing in part parameters estimated with firm-level longitudinal data. Spain is particularly interesting, since its labor regulations are among the most protective in the OECD, and both its unemployment and its share of fixed-term employment are the highest. We find that fixed-term contracts increase unemployment, reduce output, and raise productivity. The welfare effects are ambiguous.

$\begin{array}{lll}\text { César Alonso-Borrego } & \text { Jesús Fernández-Villaverde } & \text { José M. Galdón-Sánchez } \\ \text { Universidad Carlos III de } & \text { University of Pennsylvania } & \text { Universidad Publica de Navarra } \\ \text { Madrid } & \text { Department of Economics } & \text { Departamento de Economia } \\ \text { Department of Economics } & \text { 160 McNeil Building } & \text { Campus de Arrosadia } \\ \text { Av. Madrid 126 } & 3718 \text { Locust Walk } & \text { 31006 Pamplona (Navarra) } \\ \text { E-28903 Getafe (Madrid) } & \text { Philadelphia, PA 19104-6297 } & \text { SPAIN } \\ \text { SPAIN } & \text { and NBER } & \text { jose.galdon@unavarra.es } \\ \text { alonso1@eco.uc3m.es } & \text { jesusfv@econ.upenn.edu } & \end{array}$




\section{Introduction}

The consequences of job security provisions for employment, output, and welfare constitute an issue of great concern for economists and policymakers. Labor market rigidities, particularly those regarding workers' layoffs, are commonly blamed for the high European unemployment rates (see OECD, 1994, for an example of this view). Following this belief and hastened by the worsening of unemployment rates during the 1980s, several European countries undertook institutional reforms aimed at deregulating labor markets.

A common feature of these reforms was the elimination of most restrictions on the use of non-causal fixed-term (also called temporary) contracts, which are characterized by much lower firing costs than those of permanent contracts. Since their introduction, fixed-term contracts have accounted for most new hirings in all sectors and occupations (OECD, 1993). Spain, with the highest unemployment rate among the industrialized countries, is a paradigmatic case. After the 1984 reform that allowed the widespread signing of non-causal fixed-term contracts, Spain has become the European country with the highest share of temporary employment: 32 percent in 2000. In addition, temporary contracts accounted for more than 98 percent of hires in the period right after the reform. Dolado et al. (2002) provide an informative survey of the Spanish experience with fixed-term jobs.

Until now, the literature evaluating the aggregate outcome of these institutional reforms has been sparse. While their impact on flows (both job creation and job destruction have increased) and on the variability of employment (also increased) seems clear, the effect of the reforms on unemployment level and welfare is less obvious. Although firing costs reduce the level of hirings after a positive shock, firings after a negative shock are also lower. Even more important, the research on layoff cost has shown how existing quantitative results rely crucially on different modelling choices (see Ljungqvist, 2002, for a thorough discussion).

To fill this gap, this paper quantitatively studies the effects of temporary contracts. We develop a general equilibrium model with heterogeneous households and firms and incomplete markets. In our economy, households work, search, and consume subject to a set of allowed labor contracts and a borrowing constraint, while firms maximize profits. The existence of firing costs transforms the firms' problem into a non-trivial intertemporal one. We calibrate our model to Spanish data because the rate of temporality created by the reform of 1984 makes Spain a fascinating case study. An interesting point of our calibration is that some of the parameters are estimated with a dynamic partial equilibrium model and longitudinal data of Spanish firms. 
Our main finding is that eliminating temporary contracts reduces unemployment. The result is surprising since it contradicts the rationale for the labor market reforms implemented in Europe. However, the mechanism at work is transparent.

The unemployment rate is a function of the flows into and out of the pool of unemployed. Flows into unemployment are given by the rate of job separations, both job destruction and voluntary quits. Flows out of unemployment are given by successful job searches. How does the elimination of fixed-term contracts affect these flows into and out of unemployment?

The elimination of temporary labor contracts decreases the flows into unemployment because it eliminates a margin that firms exploit to adjust to productivity shocks. Firms fire temporary workers as a response to a negative shock without incurring sizeable severance costs. When temporary labor contracts are not allowed, firms are forced to smooth their employment level over time to reduce their firing costs.

The elimination of temporary labor contracts also affects the flows out of unemployment. Successful job searches depend on market tightness (the ratio between vacancies and unemployed households) and on the search effort exerted by households. Market tightness by itself is not greatly affected by the elimination of fixed-term contracts. Fewer unemployed households, coming from the lower flows into unemployment, are met by fewer vacancies, since without temporary contracts, firms also create fewer jobs in response to positive shocks (in a stationary equilibrium the job creation and destruction rates are equal).

The crucial channel, hence, is the change in search intensity. In the absence of temporary contracts, households search more intensively because the pool of jobs being offered improves: instead of most of them being temporary positions, all jobs are now permanent. Those permanent jobs are preferable because they pay a higher wage, generate severance payment in case of firing, and provide higher job security.

The combination of a higher search intensity and fewer layoffs created by the elimination of fixed-term contracts reduces the equilibrium rate of unemployment. Our result suggests that as a recipe to fight high unemployment rates, temporary contracts are a failure. Fixed-term contracts, however, increase average labor productivity, since firms respond more aggressively to shocks. The wages of permanent workers rise because the firm fires them and pays the severance cost less often, as it takes advantage of the stock of temporary workers to absorb negative shocks. A comparison of welfare across different steady states is ambiguous. Unemployed households and workers in high productivity firms win from the existence of temporary contracts, while workers in low productivity firms lose. 
Beyond our main finding, our paper makes several contributions. We are the first to develop and solve a quantitative dynamic general equilibrium model of temporary contracts calibrated to match the data of a European economy. As we will argue later, general equilibrium effects are key for the evaluation of different labor market reforms. Given the European unemployment experience and restrictive labor market regulations, calibrating the model to an economy like Spain is the empirically relevant case.

Second, our paper presents the first model with a non-trivial coexistence of permanent and fixed-term contracts. The literature so far has modelled temporary contracts as an exemption of the firing cost over the first few periods of the contract, which is otherwise identical to the labor contract that existed before the reform. However, this is not what fixed-term contracts are. Fixed-term contracts are an alternative to permanent contracts. Firms can offer a permanent contract right away to the worker, and sometimes, although admittedly not often, they do so. Conversely, workers can decide to accept only a permanent contract. The choice of a permanent or a fixed-term contract is, consequently, a decision of the agents: a choice limited by legal considerations (basically a time limitation in fixed-term contracts), but a choice nevertheless.

Our paper models this phenomenon in a natural and appealing way. Workers optimally decide to search for a permanent or a fixed-term contract. Workers with a high level of assets search for a permanent job. The advantages of such a job over a temporary one overcome the risk of not finding a job, since the household can consume out of its assets. The opposite situation prevails for workers with a low level of assets. They prefer to search for a temporary job, which is easier to find because of the higher tightness of that market. Firms pick the combination of permanent and fixed-term jobs that best suits their needs. Our paper endogenously generates the results that most new contracts are temporary and that it is easier to find a temporary job than a permanent one. These two results are noticeable empirical observations that no other model can replicate.

Third, our paper is the first to evaluate fixed-term contracts in a model with capital. Veracierto (2001) presents a compelling case for incorporating capital in the analysis of labor market regulations. If capital and labor are substitutes, the distortions of labor market regulations may be less severe. At the same time, the repercussions on the accumulation of capital of those regulations may be substantial. While the first channel lessens the impact of labor market rigidities, the second one increases them. Consequently, we need to use a model with capital to gauge the relative importance of each of these two channels. 
Fourth, our paper is the first to analyze the interaction of fixed-term contracts, incomplete markets, and risk-aversion. Most papers model fixed-term contracts with linear utility functions and/or complete markets. Such choices may miss relevant aspects of the analysis. The main goal of labor market regulations was, in the minds of policymakers who promoted them, to provide security against labor market shocks. Assuming linear utility functions and/or complete markets eliminates, by construction, any positive role of labor market regulations. Furthermore, the strong empirical evidence against full insurance (Attanasio, 1999) hints that the existing models may be providing a biased answer. We document the importance of incomplete markets and capital accumulation in the experiment where we eliminate temporary contracts. Without temporary contracts, workers face much less risk and, consequently, save less; the general equilibrium effect is an increase in the interest rate to induce workers to save more and firms to rent less capital in order to clear the capital market. Without risk aversion and market imperfections, the general equilibrium effect is lost.

Our paper, however, is not the first to assess temporary contracts. A number of previous studies have concentrated on the influence of fixed-term contracts on the dynamics of the labor market within a partial equilibrium perspective. The models conclude that fixedterm contracts boost the number of hirings and firings in the economy, while the variation of aggregate employment remains unclear. Some examples are the labor demand models by Aguirregabiria and Alonso-Borrego (1999), Bentolila and Bertola (1990), Bentolila and SaintPaul (1992), and Goux et al. (2001); the model of job creation and destruction by Cabrales and Hopenhayn (1997); or the matching economies by Blanchard and Landier (2002), Cahuc and Postel-Vinay (2002), Osuna (2005), and Wasmer (1999).

A second line of research is more empirical and addresses specific issues. The transition from fixed-term to permanent contracts has been analyzed by Booth et al. (2002) for the U.K., Güell and Petrongolo (2000) for Spain, and Holmlund and Storrie (2002) for Sweden. Nagypal (2002) probes the interaction between match-specific learning and fixed-term contracts. The changes in unemployment duration caused by temporary contracts are the focus of Boeri (1999) and Güell (2000b). Bentolila and Dolado (1994) and Saint-Paul (1996) show that a dualism in the labor market may imply a higher wage pressure if unions protect the interests of permanent workers in wage bargaining. Jimeno and Toharia (1993) and de la Rica (2004) document how temporary contracts pay a lower wage than the one that corresponds to an equivalent permanent position. 
Finally, to the best of our knowledge, there have been only three other attempts to investigate these issues in a general equilibrium framework. Güell (2000a) looks at the qualitative implications of fixed-term contracts with an efficiency wage model. She proves that fixedterm contracts may not raise employment even in a world where firing costs would reduce employment. Álvarez and Veracierto (1999a) extend an Islands model with undirected search and complete markets to deal with severance taxes conditional on tenure. They interpret this dependence as a form of temporary contracts. Veracierto (2001) uses a similar environment to appraise the short-run consequences of introducing labor market flexibility. Both papers find that fixed-term contracts may increase unemployment.

The rest of the paper is organized as follows. Section 2 gives an overview of the evolution of labor contract regulations in Europe since the 1980s and lists some stylized facts. Section 3 describes our model, and its equilibrium is defined in section 4 . We discuss our calibration in section 5 and the results in section 6 . Section 7 summarizes and advances ideas for future research. An appendix provides technical details.

\section{Stylized Facts}

The regulation of labor contracts differs among European countries (see European Commission, 1996 and 1997). For this reason, we need to define what we understand as permanent and temporary workers in the data. Permanent workers are those with contracts of indefinite duration. Temporary workers are those with a fixed-term contract. The maximum duration of the latter is usually between one and three years. Also, the application of temporary contracts is often ruled by the principle of causality, i.e., aimed at jobs that are occasional or seasonal, jobs that fill temporary vacancies, apprenticeships, and jobs for carrying out a task or service predetermined in time. Another important difference between temporary and permanent contracts is the amount of severance payments and the degree of dismissal protection in each of them. Although regulations vary, a general feature of fixed-term contracts is that severance payments and dismissal protection are low.

The adverse economic conditions in the mid-1980s, together with the complaints of entrepreneurs about the rigidity of contract regulations, led several European countries to reform their labor markets. One of the main changes was to relax the limitations on the use of temporary contracts, in particular the restrictions regarding non-causal fixed-term contracts. Among the countries in the European Union, six liberalized temporary contracts over the 1980s (the other six already had no limits on the use of temporary contracts). For instance, 
France deregulated temporary contracts in 1986, lifting the limitations on the purpose of these contracts and lengthening their maximum duration (previously between six to 12 months) up to 24 months. A counter-reform in 1990 reduced the applicability of these contracts, lowered their maximum duration to 18 months, and imposed a severance payment equivalent to 5 percent of gross salary. Germany moved in 1985 from a restrictive casuistic to a widespread allowance of temporary contracts for any new hiring and former apprentices. Also, the maximum length was extended from six months to up to two years. In Italy, fixed-term contracts were limited to seasonal and training jobs before 1987. Since then, temporary contracts have been allowed through collective agreements and prior administrative authorization. Nowadays, only Finland, Greece, and Sweden keep tight restrictions on temporary contracts (see OECD, 1994 and European Commission, 1996 and 1997).

[Table 1 here]

The extent of these reforms can be appreciated by looking at table 1, where we present the evolution in the temporality rate (share of temporary employment in total employment) in the countries of the European Union. A remarkable fact is the jump experienced by France, Portugal, and Spain, which deregulated the use of temporary contracts in the mid-1980s.

Spain, where a third of employees have a fixed-term contract, is a shocking case. Labor market regulations before 1984 were among the most protective in the industrialized world. That year, many of the previous restrictions on temporary contracts were removed, leading to their nearly unlimited use. Temporary contracts could be cancelled at termination with a low severance payment (12 days per year of tenure), ${ }^{1}$ and their extinction could not be appealed to labor courts. The maximum length of temporary contracts was set to three years. Thereafter, the firms would decide whether to offer the worker a permanent contract or to dismiss him. The reform did not introduce any change in the regulations of permanent contracts. In 1992, the minimum length of a non-causal temporary contract was set to one year, and in 1994, further restrictions on the scope of non-causal temporary contracts, related to the age and conditions of the employee, were established. In 1997, severance payments for permanent employees were reduced in order to promote the use of permanent contracts. ${ }^{2}$

\footnotetext{
${ }^{1}$ Mandatory severance payments for permanent workers were 20 days of salary per year of tenure (up to one year's wages) if the dismissal was considered "fair," and 45 days (up to 42 months of wages) if it were considered "unfair." The burden of proof for a fair dismissal fell on the firm. Labor courts tended to rule in favor of workers. See Galdón-Sánchez and Güell (2000).

${ }^{2}$ Severance payments for fair dismissals of permanent workers were maintained at 20 days of salary per year of tenure, but those for unfair dismissals were lowered to 33 days of salary.
} 
Regulation of temporary contracts is currently a controversial issue, and trade unions and the government are considering further legal regulations.

Three facts have emerged from the reforms across Europe. First, the introduction of temporary contracts does not correlate with a reduction of unemployment. Second, the entry and exit flows have substantially augmented. Finally, the elasticity of employment with respect to real GDP has risen.

[Table 2 here]

To illustrate the first assertion, in table 2, we report the correlation between the temporality and the unemployment rate using data for the EU countries from 1990 to 1996 . We estimate such correlation controlling for country-specific effects and with time dummies to account for aggregate shocks. In the first column, we report the results for the old EU-15 countries. In the second, we have excluded the three countries that were the last to join the EU-15 (Austria, Finland, and Sweden). Whereas the correlation coefficient using the full sample is positive (although marginally significant), the coefficient with the restricted EU-12 sample turns out negative, yet very small and clearly non-significant. There are three reasons to concentrate on the EU-12 results. First, there are issues of data homogeneity, since these three countries joined the EU in 1995. As an extreme case, Austria reports observations only for the last two years. Second, Finland and Sweden have two of the most restrictive legislations on temporary contracts (see OECD, 1994). Finally, these very same countries suffered from a severe recession in the 1990s, and their unemployment rates were multiplied by a factor of five in six years. Our evidence agrees with the findings in Bertola (1990), among several others, who showed no straightforward relationship between low employment and job security provisions for the major industrialized countries.

Concerning temporary contracts and job flows, OECD data show the negative correlation between job turnover and different indices of employment protection, including those related to the regulation of permanent and temporary contracts. When the index is built considering only the legal treatment of fixed-term contracts, the correlations are significantly stronger. The correlations are also robust when they are computed for establishments of different size.

Changes in labor market regulations also have a huge impact on how workers leave unemployment. OECD data document that the percentage of previously unemployed people who get a permanent contract has plummeted in countries that have implemented thorough reforms of temporary contracts (i.e., France and Spain). Countries that opted for mild re- 
forms have suffered modest reductions in that percentage (i.e., Germany and Italy), whereas in those countries in which these contracts were already deregulated, the percentage has been constant (U.K., Denmark, and the Netherlands).

Regarding the third fact- a stronger procyclical behavior of employment- Bertola (1990) and Bentolila and Dolado (1994), among others, report how temporary contracts increase labor demand in booms and decrease it in slumps, relative to the situation in which only permanent contracts are allowed.

\section{The Economy}

To explore the impact of temporary contracts on the economy, we build a dynamic general equilibrium model with heterogeneous households, firms subject to idiosyncratic shocks, and incomplete markets. Our model is in the tradition of Hopenhayn and Rogerson (1993) and, more closely, Álvarez and Veracierto (2001).

We briefly motivate the elements in the theory. First, since this is the phenomenon we want to analyze, we allow for two types of labor contracts: permanent and fixed duration, each of them with a different legal regulation.

Second, we have heterogeneous households that can save in a one-period uncontingent bond. Previous contributions have focused on models with complete markets (see Álvarez and Veracierto, 2001, and Bertola, 2004, for two exceptions). However, full risk-sharing conceals the role of employment protection as a substitute for complete markets. Empirically, unemployment spells are long (over 20 months in Spain), repeated over time, and associated with substantial consumption and future wage reductions. These observations suggest that labor risks are difficult to insure. Consequently, we believe that our framework delivers a more accurate weighting of labor market reforms. More important, in our model, households make non-trivial search decisions. Those choices are optimal given the labor market institutions. Our quantitative results show that households respond differently to variations in the regulation depending on their asset levels. A version of our economy with a representative agent would not include this margin and would produce a misleading assessment of changes in labor market policies.

Third, we introduce a simple labor market friction that provides an additional justification for job security provisions and that generates a positive unemployment rate. Households need to search to find a new job. The probability of finding a job depends on the search intensity that the household exerts and on the labor market tightness. Both effort and labor market 
tightness are endogenously determined in the model. This friction captures the matching problems of the labor market.

Fourth, we generate an endogenous cross-sectional distribution of firms subject to idiosyncratic shocks. Firms decide the division of their labor input between permanent and temporary workers as their optimal intertemporal response to shocks. In this way, we reproduce the large volume of job creation and destruction at the individual firm level and learn how the firm's dynamics and productivity are affected by labor market regulations.

Finally, we use a general equilibrium approach. We track the aggregate movements induced by the reforms because we employ the model as a measurement tool to quantitatively appraise counterfactual policies. Our findings prove that introducing fixed-term contracts has implications for the aggregate distribution of firms and workers, capital accumulation, labor supply, and factor prices. Those general equilibrium effects would be missed by a partial equilibrium analysis. We checked that, if we did not let prices adjust after the introduction of a labor market reform, we would reach strongly biased conclusions about the impact of that policy.

\subsection{Household's Problem}

The economy is populated by a continuum of households of measure one that work, consume, and save. Households experience stochastic lifetimes: in every period they face a death probability $\sigma$. When a household dies, it is immediately replaced by a new household. The assets of the dead household are taxed away by the government. The new household is born unemployed and with zero assets. Assuming that an appropriate law of large numbers holds in this economy, the mortality rate of the population is also equal to $\sigma$.

During their lives, households can be employed or unemployed. Employment can be in a permanent or in a temporary position, but both labor contracts require working the whole unit of time. ${ }^{3}$ If unemployed, the household searches for a new job with effort $e_{t} \in[0,1]$. If employed, the household cannot search for a new job, i.e., $e_{t}$ is equal to zero. We will discuss below how search operates and how effort affects the probability of finding a job. At this moment, it suffices to say that households enjoy consumption, dislike search effort, and are indifferent about the fate of future generations.

\footnotetext{
${ }^{3}$ In this paper we concentrate on full-time contracts. Interestingly enough, in most European countries in which fixed-term contracts have been introduced, part-time contracts are rare (see OECD, 1994). Nonconvexities due to commuting time or coordination problems may account for this observation.
} 
Those preferences can be represented by:

$$
E_{0} \sum_{t=0}^{\infty}(1-\sigma)^{t} \beta^{t}\left[\log \left(c_{t}^{i}\right)-\varphi e_{t}^{i}\right]
$$

where $E_{0}$ is the expectation operator conditional on information available at time $0, \beta$ is the discount factor, $c_{t}^{i}$ is consumption, and $e_{t}^{i}$ is the search effort of household $i$ at time $t$.

If we denote input prices by $r_{t}$ and $w_{t}^{i}$, where $r_{t}$ is the interest rate for assets and $w_{t}^{i}$ is the wage received by the household, the household's budget constraint for period $t$ is:

$$
a_{t+1}^{i}+c_{t}^{i} \leq\left(1+r_{t}\right) a_{t}^{i}+w_{t}^{i} I_{t}^{i}+s p_{t}^{i} J_{t}^{i}+\Pi_{t} \text { with } a_{t}^{i} \geq 0, \forall t
$$

where $I_{t}^{i}$ is an indicator function that traces whether the household works in the period, $s p_{t}^{i}$ is the severance payment that the worker receives in the case where she has been fired from a permanent position in this period (event reflected by the indicator function $J_{t}^{i}$ ), $\Pi_{t}$ is the household's share in the aggregate profits of the economy, and $a_{t}^{i}$ is the household's holding of an uncontingent bond at the beginning of the period.

The budget constraint reveals that we are closing all securities markets, except the one in which the households trade an uncontingent bond subject to a no-short-selling restriction $a_{t}^{i} \geq 0$. This market structure causes the absence of perfect insurance reported by the literature. Arguments such as moral hazard or lack of commitment explain why households cannot cover labor risks and why $a_{t}^{i}$ must be non-negative. Our market structure encapsulates the idea that labor market regulations may be a remedy for incomplete markets and that households' responses to those regulations differ according to their asset level.

\subsection{Labor Contracts}

We now describe the two labor contracts that we allow in the economy. First, we have the permanent contract. Under this arrangement, households receive a wage in each period and a severance payment in the case of dismissal. Two points deserve elaboration. First, firms cannot insure against the productivity shocks that lead to layoffs and firing costs. Thus, the argument by Lazear (1990) that if markets are complete, severance costs are neutral, does not hold. Second, contrary to the practice in most countries, we do not condition the severance payment on seniority. Otherwise, we would have a state space too large for practical computation. 
The second contract is the fixed-term one. Under this contract, firms pay a wage for one period and may offer a permanent contract at the beginning of the next. The households will come back next period to the firm and accept a permanent position if one is offered to them. We abstract from the fact that some temporary contracts can be renewed (for instance, in Spain up to three years under certain conditions). Little content is lost because the possibility of renewals of temporary workers is equivalent to changes in the period length.

It is important to distinguish the fixed-term contract from the probationary period: those initial months in the employment relationship during which a firm can terminate a contract without a severance payment because the quality of a worker is inferior to what was expected. Even before the liberalization of fixed-term contracts, European countries had probationary periods for screening purposes with durations between two and six months. Owing to the existence of a probationary period, it can be dangerous to overemphasize the role of fixedterm contracts as a screening device. Since we do not have private information, such a probation time is useless in our model. Also, a theory of temporary contracts constructed around screening has the problematic implication that, for example, one-third of Spanish workers are being tested at any moment in time.

The wages for permanent and temporary workers are given by $w_{n t}$ and $w_{m t}$, respectively. We will discuss below how these wages are determined. The two wages are common across firms. This is broadly consistent with the Spanish experience, where firms are subject to sector-wide binding agreements between the unions and the confederation of employers and industries that set the wage level for all workers, fixed-term and permanent. Firms cannot opt out of the agreement and lower wages even if they experience a negative productivity shock. This assumption transforms the level of employment in the main adjustment tool of firms. Other market structures, in which both wages and employment can adjust at firm level, will bring about different effects of labor market reforms (see Álvarez and Veracierto, 1999b).

Permanent workers quit at an exogenous rate $\omega$. We think of these quits as created by lifecycle events -marriage, maternity, migration, etc.- Voluntary quits do not accrue a severance payment. Beyond these exogenous quits, workers can leave the firm at any period, although, in equilibrium, we will not observe voluntary quits. We do not include the proof of this result because it is tedious and uninteresting. The intuition, however, is simple. Since wages are common across firms, a permanent worker cannot search for a higher wage. At the same time, the worker risks an unemployment spell of positive duration and faces the cost of search. Even 
if the household leaves the firm to avoid a future firing, it will only accelerate the negative outcome of unemployment. A similar argument shows that temporary workers will return to the firm where they worked during the last period and accept a permanent position if they are offered one.

The theory does not account for on-the-job search. In our model, if permanent workers could search on the job, they could aspire only to obtain a job with the same wage $w_{n t}$, common for all firms, but with a lower probability of being fired in the future. Similarly, temporary workers could find a permanent position for the next period, instead of hoping that the current firm would promote them at the beginning of next period. These incentives are low in comparison with the utility cost of search. Consequently, workers would not search much on the job. Given the computational costs associated with on-the-job search (firms would need to track the time-variant distribution of its workers' assets to forecast future quits due to on-the-job search), we decided to omit this channel to simplify the analysis.

\subsection{Search}

There are two labor markets for unemployed households: the market for permanent jobs and the market for temporary jobs. Effort is required to find these markets, and households can search for only one of these markets at a time.

A market maker sets the wage in each market to equalize the number of households that found the market with the number of positions available and assigns the households randomly to one of the jobs offered in that market. Our set-up follows the competitive search literature of Moen (1997) and Mortensen and Wright (2002), with the constraint that the market maker cannot condition the wage on the state variables of the worker or the firm, for example, because it cannot observe them. The market maker is equivalent to a profitmaximizing, price-taking club, which charges an entry fee for vacancies or workers. Free entry of clubs implies that entry fees are zero in equilibrium. One can also interpret the market maker as a form of price posting either by firms or by workers.

For temporary contracts, the available jobs are equal to the total temporary positions open. In the case of permanent jobs, the positions are equal to the net demand for new permanent jobs by firms, i.e., the total demand of new permanent positions less the temporary workers in the firm that are promoted. We will describe below how firms decide how many workers to hire and why the firm gives priority in filling new permanent positions to workers within the firm. 
Unemployed households choose which market they search in and how much effort $e_{t}$ to exert. The probability of finding the labor market is:

$$
p_{j}=e_{t}^{\xi} \theta_{j t}^{1-\xi} \quad \text { for } j=n, m,
$$

where $0 \leq \xi \leq 1$, and $\theta_{j t}$ is the labor market tightness, defined as the ratio between vacancies in that market, $v_{j t}$, and searchers, $u_{j t}$. This parametric form, borrowed from Pissarides (2000), embodies the idea that more effort increases the probability of finding a position, but that this probability grows at a decreasing rate, and that higher labor market tightness (fewer searchers per offered vacancy) makes it easier for households to find a job. Constant returns to scale are a natural assumption corroborated by empirical evidence (Petrongolo and Pissarides, 2001).

\subsection{Firm's Problem}

There is a measure one of firms in the economy. Each firm has access to a production function $y_{t}=\exp \left(s_{t}\right) k_{t}^{\alpha} N_{t}^{\gamma}$, where $k_{t}$ is the capital rented by the firm, $N_{t}$ is an index of efficiency units of labor defined below, and $s_{t}$ is a productivity shock. The output $y_{t}$ can be consumed, paid as hiring and firing costs, or invested in physical capital, which depreciates at a rate $\delta$ each period.

The index of efficiency units of labor is equal to $N_{t}=n_{t}^{1}+\lambda\left(n_{t}^{0}+m_{t}\right)$, a weighted sum of the workers $n_{t}$ with a permanent contract and the workers $m_{t}$ with a temporary contract. We follow the notation $n_{t}^{1}$ to denote those permanent workers that have already worked one period for the firm (either as permanents or as temporaries) and $n_{t}^{0}$ for those permanents currently working for the first time in the firm. The parameter $\lambda<1$ accounts for the lower productivity of the new workers in the firm as observed in micro data. We interpret this lower productivity as being due to firm-specific human capital that requires time to be acquired, regardless of the labor contract of the worker. ${ }^{4}$

The productivity shock $s_{t}$ follows a first-order Markov process $Q\left(s_{t}, s_{t+1}\right)$. We can also think of $s_{t}$ as the reduced form of other shocks, such as changes to demand or taxes. To ensure that an appropriate law of large numbers holds, we do not require independence of shocks across firms.

\footnotetext{
${ }^{4}$ Since ours is a model with perfect information, we do not study the possibility of temporary workers exerting high effort to get a promotion to permanent. The empirical evidence points out that the productivity of temporary workers is lower than the productivity of permanent workers after controlling for observables (de la Rica, 2004).
} 
Firms face hiring and firing costs. For the permanent worker, the hiring cost is $\theta_{n}^{H}>0$ and the firing $\operatorname{cost} \theta_{n}^{F}>0$. The firing cost represents the severance payment to the fired worker, i.e., $\theta_{n}^{F}=s p_{t}$, and the hiring cost reflects the cost of filling a vacancy, for instance, the time and money involved in a screening process. A special case is the promotion of workers from temporary to permanent. In this situation, the firm does not have to pay the hiring cost again, as the vacancy is already filled. Hence, the firm will always give temporary workers the priority to be hired as permanent workers (empirically, nearly all the firms do so). Only if the firm solicits more new permanent workers than the amount of temporary ones it had left from the previous period will it hire new permanent workers from the market. For the temporary worker, the hiring cost is given by $\theta_{m}^{H}>0$ and the firing cost by $\theta_{m}^{F}=0$. This last assumption embodies the nature of temporary contracts: their extinction is free for the firm.

The presence of hiring and firing costs makes the problem of the firm dynamic, since hiring and firing decisions in the current period will modify the profit function in the future. If the firm had $n_{t-1}$ permanent workers in the past period, it has $(1-\sigma)(1-\omega) n_{t-1}$ at hand at the beginning of the period (a fraction $\sigma$ of households dies every period and a fraction $\omega$ quits the firm). Then, if the firm wants to hire $n_{t}$ permanent workers this period, the total demand will be equal to $d_{t}=n_{t}-(1-\sigma)(1-\omega) n_{t-1}$. If the firm had $m_{t-1}$ temporary workers, the net demand of permanent workers will be $\operatorname{net}_{t}=\max \left\{n_{t}-(1-\sigma)(1-\omega)\left(n_{t-1}+m_{t-1}\right), 0\right\}$. Thus, if the productivity shock of the firm is $s_{t}$, the number of permanent workers in the last period was $n_{t-1}$ and the number of temporary workers $m_{t-1}$, the profit in period $t$ for given levels of $n_{t}, m_{t}$, and $k_{t}$ is given by:

$$
\pi\left(s_{t}, n_{t-1}, m_{t-1}\right)=\left\{\begin{array}{c}
\exp \left(s_{t}\right) k_{t}^{\alpha} N_{t}^{\gamma}-\left(r_{t}+\delta\right) k_{t}-w_{n t} n_{t}-w_{m t} m_{t}-\theta_{m}^{H} m_{t} \\
-\theta_{n}^{H} n e t d_{t}-\theta_{n}^{F} \max \left\{-d_{t}, 0\right\}
\end{array}\right\}
$$

where $N_{t}=n_{t}^{1}+\lambda\left(n_{t}^{0}+m_{t}\right)$ is the labor productivity index, $n_{t}^{0}=\operatorname{net}_{t}$, and $n_{t}^{1}=n_{t}-n_{t}^{0}$.

The intertemporal problem of the firm is given by:

$$
\max _{\left\{n_{t}, m_{t}, k_{t}\right\}} E_{0} \sum_{t=0}^{\infty} \frac{1}{(1+r)^{t}} \pi\left(s_{t}, n_{t-1}, m_{t-1}\right)
$$

where the interest rate is the firm's discount factor. In the absence of complete markets, it is not obvious that the interest rate is the right discount factor to use. However, we follow the most common practice in the literature. The profits of the firm are distributed as a lump sum to all households in the economy. 
We depart from Hopenhayn and Rogerson (1993) and Álvarez and Veracierto (2001) in that we do not consider entry and exit of firms. Since in our calibration the expected presentvalue profit of a new firm is small, we closed down that margin to simplify the model. The presence of aggregate profits ensures that consumption will also be positive (but rather small) even for unemployed households with zero assets. Picking an appropriate initial distribution of entry costs will make our model equivalent to one with entry and exit of firms. We checked that the results of the model are robust to the size of the measure of firms.

\subsection{Timing}

Since a clear grasp of timing in this model is key to understanding its behavior, we will spend a few lines describing it in detail.

\subsubsection{Households}

At the end of period $t-1$, each household is either unemployed, employed under a temporary contract that expires in that period, or employed under a permanent contract. At the beginning of period $t$, if the household survives, it observes all the information about the economy: the wages, the states of the firm where it works, and the distributions of agents. If the household dies, its wealth is taxed away by the government, and a new unemployed household is created with zero initial assets.

If the household was a permanent worker at the end of period $t-1$ at firm $j$, it goes back to firm $j$ at the beginning of period $t$ with probability $(1-\omega)$. Once there, the household either stays as a permanent worker or is fired and becomes unemployed. If it is fired or if it quits, the household chooses a market, permanent or temporary, to search for a job and an effort $e_{t}$. Given the labor market tightness and the effort, the household will find the labor market with a probability given by equation (3). If so, the household is assigned randomly to one of the jobs posted by firms and produces in the same period. Otherwise, it ends the period unemployed. We let the workers laid off at the beginning of the period find a new job within the same period to allow durations of unemployment spells lower than the period length (one year in our calibration).

If the household was a temporary worker at the end of period $t-1$ at firm $j$, it goes back to firm $j$ at the beginning of period $t$ with probability $(1-\omega)$. Once there, the household is either promoted to permanent worker or fired and becomes unemployed (there is no possibility of a renewal as temporary worker). If the household is not promoted or if it quits, it searches 
for a new job in the same way as a household that just lost a permanent job. A temporary worker can also find a job in the same period with probability given by equation (3).

Finally, if the household did not have a job at the end of period $t-1$, it decides in which job market to search and the intensity of the search effort $e_{t}$, and it will land a job with probability given by equation (3). Note that the market in which the unemployed worker searches in this period may not be the same in which it searched last period.

\subsubsection{Firms}

At the end of period $t-1$, firms know the number of permanent and temporary workers they hired and, because of quitting and mortality, firms also know that only a fraction $(1-\sigma)(1-\omega)$ will come to work in the next period. At the beginning of period $t$, firms observe wages, distributions, and their own idiosyncratic shock and decide about their new hirings or layoffs.

If the number of optimal permanent workers is equal to the number of current permanent workers, there are no hirings or firings. If the number of optimal permanent workers is larger, the firm promotes to permanent some workers who were under fixed-term contracts in the previous period and, if there do not suffice, it hires new workers. Finally, if the number of optimal permanent workers is smaller, the firm dismisses redundant permanent workers. Who is fired and who is promoted is a random choice (conditioning this decision on tenure or some other state would make the model intractable). Regarding temporary workers, at the beginning of each period, the firm recruits as many as it needs. Finally, firms produce, pay wages and interest, and distribute profits.

\section{Equilibrium}

In this section we write the problems of the households and firms with a recursive formulation and define a stationary recursive competitive equilibrium. Our concept of equilibrium will encompass the consistency of the individual states of households with the states of the firms, i.e., there should be as many households employed in firms with certain characteristics as the labor hired by firms with those states. We will call the joint stationary distribution of firms $\mu$ and households $\eta$ in the economy $P=(\eta, \mu)$. 


\subsection{Recursive Problems of the Households and Firms}

The vector of state variables for the firm is given by $\left(s_{t}, n_{t-1}, m_{t-1} ; P\right)$, i.e., the productivity shock, the amount of permanent workers and temporary workers, and the stationary distribution of agents in the economy. To emphasize that we deal with the stationary case, we use a semi-colon to separate $P$ from the other states. Also, to save on notation, we omit $P$ from our definition of the value functions and equilibrium functions below.

The vector $\left(a_{t}, s_{t}, n_{t-1}, m_{t-1} ; P\right)$ records the state variables for the employed household $i$ (we drop the superscript when no confusion occurs). Households are indexed not only by their assets and the stationary distribution of agents but also by the states of the firm in which they are employed at the end of the last period. These firm's states are relevant to computing the conditional probability of transition from permanent employment into unemployment or from temporary into permanent employment or unemployment. Our choice of state variables is equivalent to using as state variables $n_{t}$ and $m_{t}$, since, conditional on $a_{t}$, they are a deterministic function of $n_{t-1}$ and $m_{t-1}$. For an unemployed household the states are given by $\left(a_{t} ; P\right)$.

The value function $W(\cdot)$ for the firm is defined by:

$$
W\left(s_{t}, n_{t-1}, m_{t-1}\right)=\max _{\left\{m_{t}, n_{t}, k_{t}\right\}}\left\{\pi\left(s_{t}, n_{t-1}, m_{t-1}\right)+\frac{1}{(1+r)} \int W\left(s_{t+1}, n_{t}, m_{t}\right) d Q\right\}
$$

where the profit function was defined as in section 3 .

The value function of a permanent worker before hiring/firing decisions in its firm, $V^{n}(\cdot)$, can be written as:

$$
\begin{aligned}
V^{n}\left(a_{t}, s_{t}, n_{t-1}, m_{t-1}\right)= & (1-\omega) p_{1}\left(s_{t}, n_{t-1}, m_{t-1} ; P\right) \widehat{V^{n}}\left(a_{t}, s_{t}, n_{t}, m_{t}\right) \\
& +(1-\omega)\left(1-p_{1}\left(s_{t}, n_{t-1}, m_{t-1} ; P\right)\right) V^{u}\left(a_{t}+s p_{t}\right) \\
& +\omega V^{u}\left(a_{t}\right)
\end{aligned}
$$

where $p_{1}\left(s_{t}, n_{t-1}, m_{t-1}\right)$ is the (conditional) probability of staying employed as a permanent worker given the states of the firm $s_{t}, n_{t-1}$, and $m_{t-1}, 1-p_{1}\left(s_{t}, n_{t-1}, m_{t-1}\right)$ is the probability

of being laid off given the same states, $\widehat{V^{n}}(\cdot)$ is the value function of the worker that stays employed as a permanent worker, and $V^{u}(\cdot)$ is the value function of an unemployed household. The first term on the right-hand side represents the (expected) utility from keeping the permanent job times the probability of keeping it. The second term is the utility from 
unemployment when fired from the firm. Note that in this situation the household has assets $a_{t}+s p_{t}$ : the assets it brought into the period plus the severance payment. The third term is the utility from unemployment after a quit. Since this case does not accrue severance payments, the assets are equal to $a_{t}$.

In an analogous way, the value function of a temporary worker before hiring/firing decisions $V^{m}(\cdot)$ is

$$
\begin{aligned}
V^{m}\left(a_{t}, s_{t}, n_{t-1}, m_{t-1}\right)= & (1-\omega) p_{2}\left(s_{t}, n_{t-1}, m_{t-1}\right) \widehat{V^{n}}\left(a_{t}, s_{t}, n_{t}, m_{t}\right) \\
& +\left(\omega+(1-\omega)\left(1-p_{2}\left(s_{t}, n_{t-1}, m_{t-1}\right)\right)\right) V^{u}\left(a_{t}\right)
\end{aligned}
$$

where now $p_{2}\left(s_{t}, n_{t-1}, m_{t-1}\right)$ is the probability of being promoted to permanent and the complement $1-p_{2}\left(s_{t}, n_{t-1}, m_{t-1}\right)$ is the probability of being dismissed. The first term on the right-hand side represents the utility from being promoted to the permanent job times the probability of promotion. The second term represents the utility from unemployment caused either by a quit or by failure to be promoted.

The problem of the employed household that stays employed can be written as:

$$
\widehat{V^{n}}\left(a_{t}, s_{t}, n_{t}, m_{t}\right)=\max _{\left\{c_{t}, a_{t+1}\right\}}\left\{u\left(c_{t}\right)+(1-\sigma) \beta \int V^{n}\left(a_{t+1}, s_{t+1}, n_{t}, m_{t}\right) d Q\right\}
$$

subject to:

$$
\begin{aligned}
a_{t+1}+c_{t} & \leq\left(1+r_{t}\right) a_{t}+w_{n t}+\Pi_{t} \\
a_{t+1} & \geq-A, \forall t
\end{aligned}
$$

This equation reflects how the household, after being retained as or promoted to a permanent position, chooses optimally current consumption, $c_{t}$, and the next period assets, $a_{t+1}$, given its budget constraint and the new states of the firm. Since the search effort of this household is zero, we forget the linear term from the utility function. The integral in the second term of the right-hand side is taken with respect to the conditional probability of the productivity shock of the firm in which the household works.

The value function of a temporary worker after being hired in that position is:

$$
\widehat{V^{m}}\left(a_{t}, s_{t}, n_{t}, m_{t}\right)=\max _{\left\{c_{t}, a_{t+1}\right\}}\left\{u\left(c_{t}\right)+(1-\sigma) \beta \int V^{m}\left(a_{t+1}, s_{t+1}, n_{t}, m_{t}\right) d Q\right\}
$$


subject to:

$$
\begin{aligned}
a_{t+1}+c_{t} & \leq\left(1+r_{t}\right) a_{t}+w_{m t}+\Pi_{t} \\
a_{t+1} & \geq-A, \forall t
\end{aligned}
$$

The value function of an unemployed household is defined by:

$$
V^{u}\left(a_{t}\right)=\max \left\{\begin{array}{l}
\max _{e_{t}}\left\{-\varphi e_{t}+e_{t}^{\xi} \theta_{n t}^{1-\xi} \widehat{V_{n}^{N E W}}\left(a_{t}\right)+\left(1-e_{t}^{\xi} \theta_{n t}^{1-\xi}\right) \widehat{V^{u}}\left(a_{t}\right)\right\}, \\
\max _{e_{t}}\left\{-\varphi e_{t}+e_{t}^{\xi} \theta_{m t}^{1-\xi} \widehat{V_{m}^{N E W}}\left(a_{t}\right)+\left(1-e_{t}^{\xi} \theta_{m t}^{1-\xi}\right) \widehat{V^{u}}\left(a_{t}\right)\right\}
\end{array}\right\}
$$

where the unemployed household chooses in which market to search and the optimal level of search effort. Conditional on that effort, it finds a job with probability $e_{t}^{\xi} \theta_{j t}^{1-\xi}$ and stays unemployed with probability $1-e_{t}^{\xi} \theta_{j t}^{1-\xi}$.

Three new objects appear in our definition of the value function of the unemployed. The first is the expected value of a new permanent job $\widehat{V_{n}^{N E} W}(\cdot)$ given assets $a_{t}$ :

$$
\widehat{V_{n}^{N E W}}\left(a_{t}\right)=\int p_{3}\left(s_{t}, n_{t}, m_{t}\right) \widehat{V^{n}}\left(a_{t}, s_{t}, n_{t}, m_{t}\right) d P
$$

where $p_{3}\left(s_{t}, n_{t}, m_{t}\right)$ is the conditional probability of being offered a permanent job in a firm with states $s_{t}, n_{t}$, and $m_{t}$. The second object is the expected value of a new temporary job $\widehat{V_{m}^{N E W}}(\cdot)$ given assets $a_{t}$ :

$$
\widehat{V_{m}^{N E W}}\left(a_{t}\right)=\int p_{4}\left(s_{t}, n_{t}, m_{t}\right) \widehat{V^{m}}\left(a_{t}, s_{t}, n_{t}, m_{t}\right) d P
$$

where $p_{4}\left(s_{t}, n_{t}, m_{t} ; P\right)$ is the conditional probability of getting a temporary job in a firm with states $s_{t}, n_{t}$, and $m_{t}$. Finally, the value function of an unemployed household after search is:

$$
\widehat{V^{u}}\left(a_{t}\right)=\max _{\left\{c_{t}, a_{t+1}\right\}}\left\{u\left(c_{t}\right)+(1-\sigma) \beta V^{u}\left(a_{t+1}\right)\right\}
$$

subject to:

$$
\begin{aligned}
a_{t+1}+c_{t} & \leq\left(1+r_{t}\right) a_{t}+\Pi_{t} \\
a_{t+1} & \geq-A, \forall t
\end{aligned}
$$




\subsection{A Stationary Recursive Competitive Equilibrium}

A recursive stationary competitive equilibrium is a set of value functions $V^{n}(\cdot), V^{m}(\cdot)$, $V^{u}(\cdot), \widehat{V^{n}}(\cdot), \widehat{V^{m}}(\cdot), \widehat{V^{u}}(\cdot)$ and a set of associated decision rules $c(\cdot), a(\cdot), e(\cdot)$ for the household, and a value function $W(\cdot)$, and a set of decision rules $y(\cdot), k(\cdot), m(\cdot), n(\cdot)$, for the firm, factor price functions $w^{n}(\eta(\cdot), \mu(\cdot)), w^{m}\left(\eta_{t}(\cdot), \mu(\cdot)\right), r(\eta(\cdot), \mu(\cdot))$, market tightness $\theta_{n}$ and $\theta_{m}$, and aggregate laws of motion for the distribution of agents in the economy $\eta=h(\eta(\cdot), \mu(\cdot))$ and $\mu=q(\eta(\cdot), \mu(\cdot))$, such that these functions satisfy:

- the household's problem and the firm's problem;

- the aggregate laws of motion for the distribution of agents $\eta=h(\eta(\cdot), \mu(\cdot))$ and $\mu=q(\eta(\cdot), \mu(\cdot))$ described in the appendix ensure the consistency of individual and aggregate decisions;

- assets accumulated by households are equal to the demand of capital by firms:

$$
\int a(\cdot) d \eta=\int k(\cdot) d \mu
$$

- the consistency between permanent and temporary workers hired by firms and workers in a firm with the same state variables:

$$
\begin{aligned}
& \int_{a, R} d \eta^{n}=\int_{R} n(\cdot) d \mu \\
& \int_{a, R} d \eta^{m}=\int_{R} m(\cdot) d \mu
\end{aligned}
$$

where $R$ is a measurable set;

- the government satisfies its budget constraint;

- and the aggregate resource constraints and the labor market tightness definitions.

Proving the existence of an equilibrium follows standard arguments like those in Aiyagari (1994). In fact, the problem is not existence but multiplicity of equilibria. Those non-unique equilibria are of concern because they may entail contradictory statements about observables and welfare. Unfortunately, we are not able to prove uniqueness. Heuristically, and despite some effort, we failed to find alternative equilibria to the ones reported below. The working paper version of the paper (Alonso-Borrego et al., 2004) discusses this issue in more detail. 


\section{Calibration}

The benchmark economy is calibrated to reproduce characteristics of the Spanish economy during the 1990s.

The parameters of the technology of the firm $(\lambda, \alpha, \gamma, \rho$, and $\nu)$ and the hiring/firing costs parameters $\left(\phi^{F}, \phi^{P}\right.$, and $\left.\phi^{H}\right)$ come from Aguirregabiria and Alonso-Borrego (1999), who posit and estimate a dynamic programming model in a partial equilibrium framework. They use a longitudinal panel of 2356 Spanish manufacturing companies between 1982 and 1993, taken from the database of the Central de Balances del Banco de España (Bank of Spain Central Balance Sheets Office). The database contains annual information at the firm level about the number of employees by type of contract (permanent and fixed-term), the total wage bill, and other complementary information. Since, as is usual with firm-level data, there is no information on employment flows, all the estimates are based on net employment changes. Nevertheless, the information on voluntary quitting can be exploited in order to distinguish between negative employment changes due to voluntary reasons and those due to costly dismissals.

Evidence from the firm-level data reflects the existence of large adjustment costs for permanent workers. The job turnover rates are very high for temporary employees but very small for permanent ones. When the information on severance payments was exploited, it could be observed that under the definitions of firings and quits, half of the destruction of permanent jobs during 1986-1990 was due to voluntary quitting. This fact implies that most firms prefer to wait until redundant workers decide voluntarily to leave the firm rather than incur costly dismissals. Our model captures this attrition of workers through the voluntary quit rate, which we set to reproduce observed quits during the 1990s from the Spanish Encuesta de Población Activa (Labor Force Survey) to the annualized value $\omega=0.0232$.

An important issue is the wage differential between temporary and permanent workers. This concern appears because it is expected that firms with a higher share of temporary employees will pay lower wages. Ignoring this effect could introduce serious biases in the estimates. Since wages by type of contract are not observed at the firm level, the use of industry-level information is needed. With these industry-level data, it is observed that the relative wage has remained fairly constant over the estimation period.

The estimates were obtained by means of a two-stage approach. In the first stage, the technological parameters were estimated using a first-differences GMM estimator. In the estimation, an $\mathrm{AR}(1)$ process for technological idiosyncratic shocks was assumed to allow 
for shock persistence. The autoregressive process for shocks implies a relatively high degree of persistence (0.691). Computationally, productivity is approximated in our model by a five-states Markov chain.

In the second stage, the dynamic discrete decision for the sign of adjustment in permanent employment was exploited. The problem generates a Markov discrete choice model, whose log-likelihood resembles the one for a standard ordered probit, except for the key fact that the thresholds depend on the firm's expected marginal value function. The estimation method is a partial maximum likelihood estimator, developed by Aguirregabiria and Mira (2002), which consists of an algorithm that builds a sequence of pseudo-maximum likelihood estimators based on approximations to the marginal value function.

The hiring and firing parameters take account of voluntary quitting and the heterogeneity of costs between firms. To allow for additional unobservable labor costs for permanent workers, the estimation introduced a wage idiosyncratic cost, which was assumed to be iid with mean $\mu_{\varepsilon}$ and variance $\sigma_{\varepsilon}^{2}$.

The main results indicate unit firing costs that amount to 51 percent of the gross annual wage of a permanent worker, as well as unit hiring costs between 10 percent and 16 percent of gross annual wages. These estimated values are similar to those found for other European countries as in Abowd and Kramarz (2003) and Kramarz and Michaud (2004) for France.

One potential problem of the previous empirical strategy is that it used manufacturing data. Unfortunately, data to implement the previous estimation for the whole economy are not available. However, there are two reasons to think that the results from manufacturing may not be seriously biased. First, manufacturing has been a relatively stable part of the Spanish economy during the sample period. In 1985, the first year where temporary contracts where used, the weight of manufacturing in Spanish GDP was 20.16 percent. In 2000, the last year for our benchmark calibration, it was 19.37 percent, a fall of less than 1 percent in weight. Second, the temporality rate of the manufacturing sector is not very different than in the economy as a whole. For example, in 1998, the temporality rate in the whole economy was 33.06 percent while it was 29.88 percent in manufacturing. Similar differences of around 3 percent hold for all of the 1990s.

The other parameters were chosen as follows. The mortality rate $\sigma$ generates an average working life of 45 years. The depreciation rate $\delta$ was chosen to match the capital/output ratio of the Spanish economy, and the discount factor was selected to generate an interest rate of 4 percent in equilibrium. The utility cost of search effort $\varphi$ of 0.91 and the elasticity 
of the probability of finding a job to effort of 0.4 match an average duration of unemployment spells of 20.5 months, as well as an unemployment rate of 19.5 (the mean values for Spain during the 1990s). Finally, we scale $\alpha+\gamma$ (i.e., the degree of decreasing returns to scale that Aguirregabiria and Alonso-Borrego, 1999, do not pin down; they estimate the relative weight of $\alpha$ and $\gamma$ up to a scale factor) to 0.9 percent to reproduce the income attributable to entrepreneurs from the Spanish National and Income Product Accounts. We summarize our parametrization in table 3 .

[Table 3 here]

\section{Findings}

This section analyzes the effects of labor market regulations on quantities, prices, and welfare. First, we compare the equilibrium in our benchmark economy with the consequences of implementing two commonly discussed reforms: the elimination of temporary contracts and the reduction of firing costs. We also contrast our results with the efficient allocation, comment on the robustness of the results, and relate our findings to the literature. Second, we explore an alternative policy: the introduction of a subsidy for the conversion of temporary contracts into permanent positions.

\subsection{Benchmark Economy and Two Basic Experiments}

Our main findings come from the comparison between the performance of the benchmark economy and the new stationary equilibria associated with two alternative labor market reforms: the elimination of temporary contracts and the reduction of firing costs. A review of the public discussion in continental Europe explains why we find these two experiments crucial. Workers' unions forcefully lobby for limitations on the use of temporary contracts to stop job insecurity (what is famously called the "précarité": the constant rotation of workers between low-paid, low-quality temporary jobs with intermediate unemployment spells). In contrast, business associations are often on the record defending reductions in firing costs to improve the competitiveness of the European economy. Consequently, our two experiments represent movements in two opposite directions relevant to policy analysis: toward more regulation and toward increased liberalization.

We study two extreme counterfactuals: one where temporary contracts are prohibited

and one where firing costs are reduced to zero. In this last case, the figure of temporary 
contracts becomes meaningless, since now all contracts do not accrue severance payments and we can interpret all jobs as permanent. The two polar cases studied provide bounds to gauge the impact of intermediate, and politically more feasible, reforms. Sensitivity analysis reveals that the economy is monotonic: intermediate reforms produce outcomes that are in the middle of the results for the benchmark economy and a radical reform. We omit details for the shake of brevity.

An alternative exercise could be to calibrate our benchmark model to match an economy without temporary contracts and explore the effects of introducing them or of reducing firing costs. However, that experiment would imply matching data from the 1970s and early 1980s, when the Spanish economy had a very different structure and when the effects of the oil shocks were acute.

\subsubsection{Firm Dynamics}

Before exploring the effects of the two experiments on the job market, we describe firm and household dynamics under the benchmark economy and in each of the two experiments. These dynamics will ease the understanding of the results concerning the effects of labor reforms. In this subsection, we study the response of firms to productivity shocks. In the next subsection, we study household dynamics.

Firms adjust their employment levels to productivity shocks. It is instructive to begin by thinking about an economy without any hiring or firing costs. In this simple environment, the firm just hires or fires every period the amount of workers required to equate marginal labor productivity to wages in the market. Higher productivity will trigger hirings, and lower productivity will cause layoffs. When we introduce severance payments (as in the experiment without temporary contracts) and hiring costs (both in the experiment without temporary contracts and in the experiment without firing costs), firms follow a generalized $S s$ rule: they will hire or fire workers only when the change in productivity is large enough so as to compensate for the hiring or firing costs.

The most interesting dynamics arise when we have hiring and firing costs and temporary contracts. As in the previous case, higher productivity implies a higher target for employment, and lower productivity, a lower target for employment. However, the presence of temporary contracts creates a particular policy rule for those adjustments. We study first the case of a positive technology shock. In that situation the firm uses temporary workers to increase production at impact. Why? Because their productivity will be the same as the productivity 
of new permanent workers, while they are cheaper both in terms of wages and in terms of no severance payment (relevant here since the mean reverting character of the technology shock implies high expected firings in the future). In the next period after impact (and assuming productivity stays at the same level), the firm promotes a fraction of the temporary workers, since they now enjoy the high productivity delivered by experience. If any further labor is required, the firm hires additional temporary workers. If, in the second period after impact, productivity stays at the same level, a further fraction of temporary workers are promoted to permanent, and so on. As the firm keeps enjoying a high productivity level, it moves toward a mix with a higher proportion of permanents. Even after the end of the adjustment, a firm keeps a percentage of fixed-term contracts to prevent future severance payments. Thus, firms expand with temporary jobs, except when the productivity shock is so large that it induces them to hire a few extra permanent workers to save on future recruiting costs. However, this happens with very low probability, creating the minuscule rate of direct hirings of permanent workers that we observe in the data. In the case of a negative productivity shock, the firm fires as many temporary workers as needed at impact and (depending on the size of the drop in productivity) some permanent workers.

From our previous description we have seen how the dynamics of hiring and firing share a common theme: adjustment is done basically through temporary workers. Permanent workers are hence cushioned against most productivity shocks by the presence of temporary workers. Also, we can see how the temporary workers create asymmetric dynamics for expansions and contractions. When the firm experiences a positive technology shock, it expands cautiously, using the temporary workers to grab much of the advantages of higher technology but without too much of a commitment in terms of future severance payments. However, when the firm is hit with a negative shock, it can slash production quickly and cheaply by laying off its temporary workers. This result is suggestive of the possible relevance of temporary contracts to explain changes in the variability of the business cycle. Unfortunately, computational limitations preclude us from exploring this channel in more detail.

\subsubsection{Household Dynamics}

Household dynamics involve two decisions: how much to save (i.e., how many bonds to accumulate) and how much and in which market (permanent or temporary) to search when unemployed. 
With respect to the first choice, households accumulate bonds for self-insurance purposes. They increase their bond holdings when they are temporary workers, since they will face, with certain probability, an unemployment spell in the next period. When they are permanent workers they accumulate (or disaccumulate) bonds up to a level determined by the interest rate and the states of the firm, since those states affect the household's risk of being fired.

[Figure 1 here]

With respect to search, figure 1 plots the optimal effort as a function of assets. We plot two lines: a continuous one for the search effort in the permanent market, and a dotted one for the search effort in the temporary market. The negative slope of both curves is a consequence of utility smoothing: when assets are high, the marginal utility of a wage is lower than the cost of additional effort. The steepness of the negative slope is given by the cost of effort, $\varphi$, and by the elasticity of the probability of matching with respect to effort, $\xi$.

Figure 1 illustrates how heterogeneity among workers with respect to asset holdings and incomplete markets induces a self-separation of unemployed households into two search pools; one that looks for temporary jobs, and one that searches for permanent jobs. The vertical line divides the state space into two regions. To the left, we have the region of low asset level, where households search for temporary jobs. Those households suffer relatively more from unemployment because their ability to smooth consumption is limited by their low asset level. Hence, they decide to search in the temporary labor market, where it is easier to find a job because the tightness of the market is higher (there are 0.59 temporary vacancies open for each searcher), and they search with high intensity. To the right, we have the region of those households with a high asset level. Those households prefer to search for a permanent job, even if the probability of finding one is low (there are 0.21 permanent vacancies open for each searcher) because these jobs are better: they offer a higher wage, and they are, on average, in firms with higher productivity and thus lower probability of future firings. As an unemployment spell progresses without finding a job, households may move from the second region into the first as they finance their consumption by reducing their asset levels.

Armed with our understanding of firm and household dynamics, we report now the effects of the two computational experiments on quantities, prices, and welfare. 


\subsubsection{Aggregate Quantities}

Table 4 reports selected aggregate quantities for the benchmark economy and the two experiments. We have normalized the benchmark economy's values to 100. The first row compares output. A striking finding is that output goes up 5.5 percent when temporary contracts are eliminated. The higher output comes from an increased level of employment and not from a better use of inputs, since average labor productivity falls 4.4 percent. The result proves that when fixed-term contracts are prohibited, the reductions in productivity due to the misallocation of workers (too many workers in low productivity firms and too few in high productivity firms) overtake the benefits of less rotation and the smaller loss of firm-specific human capital. The finding contradicts the common complaint of workers' unions that temporary contracts create so many low-quality jobs that they end up decreasing productivity. If firing costs disappear, output roughly stays constant: a noticeably higher productivity (2.7 percent) created by better allocation of resources and more capital accumulation is compensated by a lower labor input (2.3 percent) induced by the higher unemployment rate. Note that in this case, as in the other findings of the paper, the results of the benchmark economy are always between the results for the two experiments. This is natural because the benchmark economy represents an intermediate step between the two extremes of no temporary contracts and no firing costs.

[Table 4 here]

The capital-output ratio moves in opposite directions in each reform. In the experiment where firing costs are eliminated, additional capital is accumulated to take advantage of the higher mean productivity and of the lower interest rate (see table 5 below). Thus, the capital/output ratio increases 1.6 percent. In the experiment where temporary contracts are eliminated, capital is relatively more attractive because firms can vary their capital stock freely, while labor is more expensive to adjust. However, the general equilibrium effects induce an interest rate increase (see again table 5 and our explanation for this effect below). Such increase reduces the amount of capital rented by firms by an even bigger amount. The final outcome is a fall in the capital/output ratio of 4.2 percent.

The impact on hiring and firing costs is simple: they go down in both experiments- in the case were temporary contracts are eliminated, because of reduced rotation; in the economy with no firing restrictions, because the only costs left are those that come from hiring. 
Profits go up under both reforms: 6 percent without temporary contracts, and 16 percent without firing costs. The reason why profits rise when firing costs are eliminated is straightforward: firms can respond better to productivity shocks by adjusting the number of workers they hire. This increase in profits explains why firms strongly oppose firing costs and lobby for their elimination. The reason for the increase of profits when no temporary workers are allowed comes from general equilibrium effects. As we will describe momentarily, wages go down in a world without temporary contracts. The reduction in wages is enough to compensate the lower productivity of workers and the higher interest rate. Thus, the elimination of temporary contracts pushes profits up through lower wages.

However, although we find that firms' profits slightly increase with the elimination of temporary contracts, our number is biased upward. Since we do not consider aggregate uncertainty, the cost of rigidities is undervalued. By the opposite argument, the increase in profits with the elimination of firing costs is biased downward, since ignoring aggregate uncertainty makes flexibility less valuable.

\subsubsection{Prices}

Table 5 reports prices where all wages are expressed in relation to the wage of permanents in the benchmark economy. When temporary contracts are eliminated, the wage of permanents goes down 7.5 percent. If we compare the average wage in both economies (i.e., considering that in the benchmark economy 32 percent of workers are temporaries with a lower wage), the reduction of the average wage is 4.1 percent. The wage falls when we eliminate temporary contracts because both the higher amount of workers with a job and the lower capital/output ratio reduces labor productivity. Moreover, the lower wage compensates firms for the higher average adjustment cost of labor. The drop in wages rationalizes why even if unions have been vocal opponents of temporary contracts, they have not marshalled all their might to eliminate them.

\section{[Table 5 here]}

In the absence of firing costs, the wage goes up 3.4 percent, but workers have to face unemployment spells more often and they do not receive severance payments. In the nofiring costs economy, all the workers can be thought of as permanent: there is no time limit on the labor relation even though it may be terminated at will. 
In the benchmark economy, a temporary contract implies a wage disadvantage of 11 percent plus the risk of not being promoted: only 44.8 percent of temporary workers become permanents in the same firm. The wage disadvantage is roughly equivalent to the difference observed in Spain (de la Rica, 2004). The promotion rate implies between two and three unemployment spells, on average, before a household achieves a permanent position. The result shows how the theory accounts for two observations. First, the repeated cycles of temporary employment/unemployment of the same worker. Second, the reduction in future wages after the layoff of a permanent worker. Since nearly all new contracts are temporary, the expected wage of the worker is lower than the one before being fired.

The interest rate increases to 4.7 percent in the economy without temporary contracts. In the absence of these temporary contracts, workers face much less risk and, consequently, save quite less; general equilibrium requires an increase in the interest rate to induce workers to save more and firms to rent less capital in order to clear the capital market. The opposite case happens when we eliminate firing costs. Since workers face higher risk (and no severance payments right when the negative shock of unemployment hits), households save more. The interest rate falls to clear the market for capital through lower savings and higher demand for capital. The results for the evolution of the interest rate highlight the importance of accounting for general equilibrium effects and market incompleteness to evaluate the impact of a labor market reform.

\subsubsection{Job Market}

The outcomes for the job market are summarized in table 6 . The benchmark economy matches the unemployment rate (19.49 percent) of Spain during the 1990s. This is not surprising, since we calibrated the economy to reproduce this observation. More interesting is the fact that the model delivers a temporality rate, 32.25 percent, basically equal to the observed mean during the same period (33.06 percent). Since we did not calibrate the model to achieve this goal, we interpret the result as a confirmation that the model is a good laboratory for policy analysis. As mentioned above, we also match the fact that nearly all new contracts are temporary: less than 1 percent of new hirings are permanent.

[Table 6 here]

What happens when we reform the labor market? First and most important, unemployment goes in the opposite direction than commonly argued. The elimination of temporary 
contracts reduces unemployment from 19.49 percent to 11.10 percent, while phasing out firing costs increases it to 21.78 percent.

Why is that? Unemployment is a function of how many households become unemployed in one period and how long they stay unemployed. The first component depends on how many jobs are destroyed during a period plus mortality and voluntary quits. When we eliminate temporary contracts, the destruction rate falls from 31.53 percent to 19.33 percent because of the higher marginal cost of firing workers. When we eliminate firing costs the destruction rate increases to 35.56 percent. Our previous description of the firm dynamics helps us to understand those changes in destruction rates. When temporary contracts are eliminated, firms are more reluctant to destroy (and, conversely, to create) jobs when negative (positive) technological shocks arrive, since firms do not enjoy the low-cost adjustment margin of temporary contracts. Similarly, in the absence of firing costs, firms react even more than in the benchmark economy to productivity changes, increasing the rate of job destruction.

How long do households stay unemployed? This is a function of the effort exerted by households and the market tightness. We now look at each of these two channels.

When temporary contracts are eliminated, not much action comes directly from market tightness. In the new steady state there are 0.62 vacancies open for each searcher. This compares with the economy with temporary contracts, where there is an average of 0.58 vacancies open for each searcher (0.59 temporary vacancies and 0.21 permanent vacancies, with around 40 times more temporary vacancies than permanent vacancies). Market tightness stays roughly constant because, even if the number of jobs offered decreases (since in a stationary equilibrium they must be equal to the number of jobs destroyed), the number of searchers also decreases.

However, even if the market tightness is roughly the same, there is an important difference: the tightness of 0.62 now refers to the search for a permanent job. Consequently, from the household's perspective, the correct comparison point is the 0.21 permanent vacancies per searcher of the benchmark economy. This difference has an important effect in search intensity and, thus, on the length of unemployment spells.

[Figure 2 here]

Figure 2 plots the search effort as a function of assets for the benchmark case (continuous line for searchers in the permanent market and discontinuous for searchers in the temporary market), for the experiment where we eliminate temporary contracts (line with crosses), and 
for the experiment where we eliminate firing costs (line with squares). In figure 2 we can see how the optimal search effort is higher in the economy without temporary contracts for all asset levels. The reason for the higher effort is simple. When the temporary contracts are eliminated, the probability of finding a permanent job is higher, and consequently, the return to searching is also higher. Households respond to the higher return to search by exerting considerably more effort. The combination of lower destruction rate and higher effort by households results in a fall of unemployment of nearly eight-points and a reduction in the average unemployment spell of nearly two months.

Figure 2 also illustrates why unemployment increases when firing costs are eliminated. In this experiment, all new jobs lose quality jobs in the sense that the probability of being fired from them is higher. Thus, households search less than in the benchmark economy. The search effort in this experiment is below the search effort for temporary workers in the region where households in the benchmark economy search for temporary jobs and below the search effort for permanent jobs in the region where households in the benchmark economy search for permanent jobs. This lower search intensity, combined with the previously discussed higher rate of job destruction when firing costs are eliminated, accounts for the two-point increase in the unemployment rate.

Finally, the last line of table 6 shows that, in the benchmark economy, less than one percent of the new jobs created are permanent. All the other permanent jobs are created as temporary jobs and later become permanent. This number is interesting because it resembles the Spanish experience, where less than 2 percent of the new jobs created are permanent and where most permanent positions are now filled as internal promotions from fixed-term contracts into permanent jobs.

Our results may explain why it has been difficult to find a negative correlation between job market flexibility and unemployment rates (see Lazear, 1990 or Nickell, 1997): higher flexibility in the job market is good for productivity, but it has ambiguous, if not negative, implications for aggregate employment. Also, in the working paper version of this paper (Alonso-Borrego et al., 2004), we argue the history of Spanish unemployment is compatible with the effects that our model predicts after a liberalization and latter partial reversal of the applicability of temporary contracts. Furthermore, our model helps us to understand the evolution of Spanish productivity that is otherwise difficult to account for. In the interest of space, we omit detail here. 


\subsubsection{Welfare}

Undertaking welfare comparisons in the model is complicated because the transitions from one stationary equilibrium to the other after a policy change are too difficult to compute. Consequently, we can only compare the welfare between steady states and not account for the whole transitional dynamics that will generate some "winners" and "losers" of any reform. Subject to these two caveats, we discuss two findings. The great winners of the elimination of temporary contracts are unemployed households, especially those with low assets. Thanks to the reform, they can escape the cycle of temporary jobs/unemployment spells in which they are trapped. In the new equilibrium, they find a job more quickly (the labor market tightness is higher and their effort is higher) and when they do, they find a permanent one. The great losers are the households that are permanent workers in a firm with a good technology shock. In a world with temporary contracts, these households suffer a low probability of being fired, since there is a buffer of temporary workers that will be dismissed before the cuts hit the permanents. In an environment without temporary workers that buffer shocks, permanent workers are more exposed to layoffs.

\subsection{Comparison with Efficient Allocations}

To understand our results, it helps to compare them with the outcome of an efficient allocation. There are two sources of inefficiency in our benchmark economy. First, market incompleteness prevents full insurance across households. Second, there are search externalities. The higher the search effort of a household, the higher is its probability of finding a job. When that household leaves the unemployment pool, it increases the tightness of the market and raises all other unemployed households' probability of finding a job. Since households are not rewarded for this externality, there will be, in general, too little search effort in the benchmark economy. Similarly, firms fire too many employees in response to a negative productivity shock because they do not internalize the crowding effect that those new unemployed households generate in the labor market.

In the efficient allocation, the social planner provides full insurance to households and internalizes the search externalities, both of households and of firms (although, of course, the social planner still considers the costs associated with those activities when choosing the optimal level of search and hirings/firings).

One first finding is that, consequently, the social planner pushes the effort of households much higher than in the benchmark economy. It asks each searcher to exert an effort of 0.978 
(because of full insurance, all households search with the same intensity). Comparing this effort with figures 1 and 2, we can see the sharp difference that the search externality induces. A second finding is that the social planner reduces the rate of job destruction to 29 percent.

The combination of a dramatically higher search effort and a lower job destruction rate generates a fall in the unemployment rate to 0.5 percent and an increase in output of 19.4 percent. Productivity falls 3.5 percent because of the higher number of employed workers, not totally compensated by an increase in capital (the capital/output ratio falls from 1.70 in the benchmark economy to 1.66 in the efficient allocation).

The comparison with the efficient allocation reinforces, once more, the main message of our paper. The key mechanisms at work in our model are the job destruction rate and the search effort. The job destruction rate is too high and the search effort is too low. Limiting the ability of agents to use fixed-term contracts reduces the job destruction rate and increases the search effort, leading the economy closer to the efficient allocation. Conversely, reducing firing costs has the opposite effect and worsens the allocation.

\subsection{Robustness of Results}

How robust are our results? The basic mechanism in the model that generates a fall in unemployment when temporary contracts are eliminated survives changes in parameter values. The fall in unemployment comes from lower job destruction and from a higher intensity in search. These two channels hold for the empirically reasonable region of parameter values and for changes in some of the details of the model.

For example, we did not include an unemployment insurance system for the shake of simplicity. The Spanish unemployment coverage is limited, especially for those workers with temporary contracts. More important, the main effect of unemployment insurance is to decrease the exit rate from unemployment. Consequently, to calibrate the economy to match the observed average duration of unemployment, we would need to lower the search cost. But once this has been taken care of, we checked that the economy behaves in nearly the same way as in the case without unemployment insurance. Firms still change their job destruction/creation rates in the same way when temporary contracts are eliminated and the households increase their search effort because the quality of the pool of jobs improves. ${ }^{5}$

\footnotetext{
${ }^{5}$ There is one aspect, though, that could change the behavior of the model: the financing of unemployment insurance through distortionary taxation instead of a lump-sum tax. We did not explore this possibility since it would have led to a whole different range of issues outside the scope of the paper.
} 
A similar argument can be established for the absence of intergenerational and/or intragenerational transfers that some researchers have pointed out as an important factor behind European unemployment (Fogli, 2000). If we had those transfers, we would need to recalibrate the search cost to a lower value to match the average unemployment rate, but the main mechanism in the model would stay the same.

Another characteristic to which the main results of the model are robust is the borrowing constraint. We can ask the question: what would happen if institutional arrangements changed and households could borrow? Allowing net borrowing, for example, of around one year of wages, decreases the amount of effort exerted by unemployed households at any level of assets. The reason is that the risk of continued unemployment is less costly in terms of utility, since borrowing will allow households to smooth consumption. This channel would increase the unemployment rate. However, households that are currently working will also accumulate fewer assets. The reason is that the main objective of saving -providing self-insurance- is less important in a world with borrowing. Hence, the cross-sectional distribution of households shifts to the left of the asset level. But we need to remember that, as we can see in figures 1 and 2, the search effort function is a decreasing function of assets. Thus, on average, households will exert more effort because they enter unemployment with fewer assets. These two effects (less effort because unemployment is less costly and more effort because households enter into unemployment with less assets) cancel each other, delivering roughly the same quantitative results as in our benchmark economy.

More problematic is the absence of technological change. Our environment is stationary: firms get better or worse producing a uniform good under a constant technology. In an environment with technological advances, firing restrictions may decrease the expected value of an innovation because of the lack of flexibility in exiting the market if the new idea is not profitable (see Saint-Paul, 2002, for a similar argument). Reduced innovation may lead to sizable welfare losses and may be a more important reason behind the so-called Eurosclerosis than the disadvantages of firing restrictions for established firms. We see this area as a field for further research. 


\subsection{An Alternative Experiment}

Our model provides a flexible framework to assess alternative labor market reforms. Because of space considerations, we present a brief summary of results from only one further experiment.

We evaluated a subsidy to convert fixed-term contracts into permanent ones. The government pays the subsidy to firms from revenue raised by a lump-sum tax. The experiment is motivated by the introduction of such a measure in Spain during the period 1997-1999. The reform of 1997 in Spain lowered the payroll tax paid by employers between 50 to 60 percent (depending on the circumstances) of its usual level during 24 months and 20 percent for another 12 months if the firm converted temporary contracts into permanent contracts. Given that the regular payroll tax rate paid by the employer was 31 percent of the wage, the reduction amounted to around a third of the yearly wage. However, the subsidies were greater for some workers, and additional payments were made through other programs. To round up all those transfers, in our experiment, we subsidize the conversion of temporary contracts to permanents by 50 percent of the yearly wage.

A transitory subsidy, like the one implemented in Spain, does not have any long-run impact in our model: after a few periods, firms return to their original employment mix. More revealing is the new steady state if we keep the subsidy over time. Our main finding is that unemployment rises to 21 percent. The reason is that, with the subsidy, temporary workers become relatively cheaper. If they are fired after the period, the cost to the firm is the same as before the introduction of the subsidy (up to the changes induced by general equilibrium effects). If they are promoted, the firm receives 50 percent of the yearly wage. Since temporary workers become relatively cheaper, firms change their mix of permanent/fixed-term toward a higher proportion of fixed-term workers. Given that temporary workers are rotated more often, the subsidy induces a larger flow into the unemployment pool. The flows out of unemployment are a bit smaller because the change in the mix of jobs toward more temporary workers reduces the incentives for exerting search effort. The combination of higher flows into unemployment and less search when unemployed results in the higher unemployment rate reported above. Another way to think about this result is that since matching is costly, a subsidy that increases the amount of workers searching without raising productivity will reduce welfare. We conclude from our experiment that the policy of subsidizing the conversion of fixed-term contracts into permanent contracts is unlikely to have a long-run positive effect. 


\subsection{Comparison with the Literature}

We can compare our results with previous findings in the literature. Hopenhayn and Rogerson (1993) compute that a tax on job destruction equal to one year's wages reduces employment roughly 2.5 percent, and the cost in terms of consumption of this same tax is greater than 2 percent. Díaz-Moreno and Galdón-Sánchez (1999) calibrate that model economy to Spanish data. They report that reducing the dismissal tax from the equivalent of one year of wages to zero would increase employment 8.13 percent and productivity 2.28 percent. Our model is different from these papers because we do not have an efficient allocation in the absence of labor regulation. In Hopenhayn and Rogerson the firing costs cannot be a positive policy: they reduce productivity and, through this effect, labor supply. Álvarez and Veracierto (2001) also document severance taxes' large and positive effects on employment and welfare because of the same mechanism we emphasize: the reduction in frictional unemployment induced by the lower flexibility of the labor market. The increment of unemployment in our model when firing costs are eliminated is smaller than in Álvarez and Veracierto (2001) because in our benchmark economy there is already a lot of flexibility in adjusting the level of employment by firms without severance costs through the temporary contracts. Then, it is natural to expect a lower effect of eliminating these severance payments.

Another paper related to ours is that of Blanchard and Landier (2002). These authors also find that fixed-term contracts may induce higher unemployment, lower output, and lower welfare. Their model, however, emphasizes the uncertainty about the quality of the match. The introduction of temporary contracts makes firms more selective: even relatively good matches are dissolved at the end of the fixed term, since trying out a new worker is cheap. The mechanism in our paper stresses firms' response to productivity shocks and households' search effort. We argued before that this channel might be more important than screening, since, even before the arrival of fixed-term contracts, firms had access to probationary periods during which the quality of the match could be appraised without incurring a severance cost. Moreover, the magnitude of temporary contracts in Spain is difficult to reconcile with a history centered on screening. 


\section{Conclusion}

What are the quantitative effects of temporary contracts on the economy? Our exercise shows that they increase unemployment. Armed with a flexible instrument to raise or lower output, firms increase job flows. Since searching for a new job takes time, these higher flows generate a higher unemployment rate in equilibrium. The counterbalancing force of higher productivity allowed by the quicker adaptation to productivity shocks is not strong enough to turn the result around. This is an example of second-best reasoning: in a world where markets are characterized by frictions, introducing flexibility at the margin does not necessarily deliver an improvement in welfare.

To keep the model tractable and computationally feasible, we have abstracted from several important features of the data. First, we have excluded any interaction between fixedduration contracts and the business cycle. Intuition hints that aggregate fluctuations can be magnified if firms acquire with the fixed-duration contracts an additional margin to adapt to a common shock. Second, we have not investigated how temporary contracts modify the wage-bargaining process. It has been argued that the presence of fixed-duration workers strengthens the bargaining power of permanent employees, since the firm will prefer to lay off the temporary workers first when a bad shock hits. However, in a dynamic framework, the presence of fixed-duration contracts will shift the average composition of employment. This shift may reduce the bargaining power of permanent workers. Third, we have not modelled the feedback between fixed-term contracts and private information. Fourth, we do not specify any ex-ante heterogeneity among households. Differences in productivity across workers or a life-cycle component may vary the importance of temporary contracts. Finally, we have omitted any political-economic considerations that could explain why these contracts appeared in Europe during the 1980s instead of other types of reforms. All these issues are worth exploring in future research to cast further light on why Europe ended up with the high and persistent unemployment rates it suffers today. 


\section{Appendix}

This appendix describes in detail the laws of motion for the measures of households and firms and outlines the algorithm used in the computations.

\subsection{Laws of Motion for the Measures of Agents}

Now we present in detail the laws of motion $h^{n}(\cdot)(\eta(\cdot), \mu(\cdot))$ and $q(\cdot)(\eta(\cdot), \mu(\cdot))$ for the measures of households and firms.

The cross-sectional distribution of households, $\eta$, has three parts: households employed in a permanent position $\eta^{n}$, households employed in a temporary position $\eta^{m}$, and unemployed households $\eta^{u}$. Each part has its own law of motion, such that $h(\cdot)(\eta(\cdot), \mu(\cdot))=$ $\left\{h^{n}(\cdot)(\eta(\cdot), \mu(\cdot)), h^{m}(\cdot)(\eta(\cdot), \mu(\cdot)), h^{u}(\cdot)(\eta(\cdot), \mu(\cdot))\right\}$.

The first component satisfies:

$$
\begin{aligned}
\eta^{n}\left(a^{\prime}, s^{\prime}, n^{\prime}, m^{\prime}\right)= & h^{n}\left(a^{\prime}, s^{\prime}, n^{\prime}, m^{\prime}\right)(\eta(\cdot), \mu(\cdot)) \\
= & \int_{a^{\prime}=a(\cdot), n^{\prime}=n(\cdot), m^{\prime}=m(\cdot)}(1-\sigma)(1-\omega) p_{1}(s, n, m) \eta^{n}(a, s, n, m) Q\left(s, s^{\prime}\right) d \eta^{n}+ \\
& \int_{a^{\prime}=a(\cdot), n^{\prime}=n(\cdot), m^{\prime}=m(\cdot)}(1-\sigma)(1-\omega) p_{2}(s, n, m) \eta^{m}(a, s, n, m) Q\left(s, s^{\prime}\right) d \eta^{m}+ \\
& \int_{a^{\prime}=a(\cdot), n^{\prime}=n(\cdot), m^{\prime}=m(\cdot)}(1-\sigma) p_{3}(s, n, m) e(a)^{\xi} \theta_{n}^{1-\xi} \eta^{u}(a) \chi(a) Q\left(s, s^{\prime}\right) d P
\end{aligned}
$$

The first integral keeps track of households that keep their job as permanents, the second, the households that are promoted from temporary to permanents, and the third one the unemployed households that find a job as a permanent (and $\chi(a)$ is an indicator function that takes value one for those households that search in the permanent market).

The second component $\eta^{m}$ satisfies:

$$
\begin{aligned}
\eta^{m}\left(a^{\prime}, s^{\prime}, n^{\prime}, m^{\prime}\right) & =h^{m}\left(a^{\prime}, s^{\prime}, n^{\prime}, m^{\prime}\right)(\eta(\cdot), \mu(\cdot)) \\
& =\int_{a^{\prime}=a(\cdot), n^{\prime}=n(\cdot), m^{\prime}=m(\cdot)}(1-\sigma) p_{4}(s, n, m) e(a)^{\xi} \theta_{m}^{1-\xi} \eta^{u}(a)(1-\chi(a)) Q\left(s, s^{\prime}\right) d P
\end{aligned}
$$

In this equation we have only one component because temporary workers cannot be renewed as temporaries if they do not promote. 
The third component satisfies:

$$
\begin{aligned}
\eta^{u}\left(a^{\prime}\right)= & h^{u}\left(a^{\prime}\right)(\eta(\cdot), \mu(\cdot)) \\
= & \int_{a^{\prime}=a(\cdot)}(1-\sigma)\left(\omega+(1-\omega)\left(1-p_{1}(s, n, m)\right)\right) \eta^{n}(a, s, n, m) d \eta^{n}+ \\
& \int_{a^{\prime}=a(\cdot)}(1-\omega)(1-\sigma)\left(1-p_{2}(s, n, m)\right) \eta^{m}(a, s, n, m) d \eta^{m}+ \\
& \int_{a^{\prime}=a(\cdot)}(1-\sigma) \eta^{u}(a) \tau(a) d \eta^{u}+\sigma I_{a^{\prime}=0}
\end{aligned}
$$

where $\tau(a)$ is an indicator function with value 1 for those unemployed households that do not find a job, and the last term $\sigma I_{a^{\prime}=0}$ keeps track of the new households born with zero assets.

The cross-sectional distribution of firms satisfies:

$$
\mu\left(s^{\prime}, n^{\prime}, m^{\prime}\right)=q\left(s^{\prime}, n^{\prime}, m^{\prime}\right)(\eta(\cdot), \mu(\cdot))=\int_{n^{\prime}=n(\cdot), m^{\prime}=m(\cdot)} \mu(a, s, n, m) Q\left(s, s^{\prime}\right) d \mu
$$

\subsection{Computational Algorithm}

This appendix describes an algorithm to compute the stationary equilibrium of our benchmark economy. This procedure is interesting because it ensures that the two different measures, the distribution of firms and the distribution of households, are consistent with each other. Adapting our algorithm to the various experiments in the paper is straightforward.

The basic structure of the algorithm is as follows:

1. Guess some equilibrium prices $w_{n}, w_{m}, r$, and labor market tightness. A good initial guess implies a ratio of permanent/temporary wages close to, but below, the ratio of productivities.

2. Given prices, solve the problem of the firm. Since the problem is not convex, we discretize the state space and the choices.

3. Find the stationary distribution of firms given the solution to the previous step.

4. Get the transition probabilities for the households implied by the stationary distribution of firms.

5. Given the transition probabilities in (4) and the prices, solve the household's problem. 
6. Find the stationary distribution of households induced by (5) and the transition probabilities found in step (4). Note that using these model-consistent probabilities will imply that the stationary distribution of households will assign mass only to those points that have a positive mass of firms. Also, the mass of workers will be consistent, point by point, with the mass of firms.

7. Use the stationary distributions of firms and households to check for market clearing. 8. Update (1) and continue until all three markets clear. 


\section{References}

[1] Abowd, J.M. and F. Kramarz (2003), "The Cost of Hiring and Separations". Labour Economics 10, 499-530.

[2] Aguirregabiria, V. and C. Alonso-Borrego (1999), "Labor Contracts and Flexibility: Evidence from a Labor Market Reform in Spain". Universidad Carlos III de Madrid, Working Paper 99-27.

[3] Aguirregabiria, V. and P. Mira (2002), "Swapping the Nested Fixed Point Algorithm: A Class of Estimator for Discrete Markov Decision Models". Econometrica 70, 1519-1545.

[4] Aiyagari, R. (1994), "Uninsured Idiosyncratic Risk and Aggregate Saving". Quarterly Journal of Economics 109, 659-684.

[5] Álvarez, F. and M. Veracierto (1999a), "Firing Taxes and Temporary Contracts in an Equilibrium Search Model". Mimeo, Federal Reserve Bank of Chicago.

[6] Álvarez, F. and M. Veracierto (1999b), "Labor-Market Policies in an Equilibrium Search Model". NBER Macroeconomics Annual 1999, 265-303.

[7] Álvarez, F. and M. Veracierto (2001), "Severance Payments in an Economy with Frictions". Journal of Monetary Economics 47, 477-498.

[8] Alonso-Borrego, C., J. Fernández-Villaverde, and J.E. Galdón-Sánchez (2004), "Evaluating Labor Market Reforms: A General Equilibrium Approach". Penn Institute for Economic Research Working Paper 2004-16.

[9] Attanasio. O.P. (1999), "Consumption" in J.B. Taylor and M. Woodford (eds), Handbook of Macroeconomics, Volume 1B.

[10] Bentolila, S. and G. Bertola (1990), "Firing Costs and Labor Demand: How Bad Is Eurosclerosis?". Review of Economic Studies 57, 381-402.

[11] Bentolila, S. and J.J. Dolado (1994), "Labor Flexibility and Wages: Lessons from Spain". Economic Policy 18, 53-100.

[12] Bentolila, S. and G. Saint-Paul (1992), "The Macroeconomic Impact of Flexible Labor Contracts, with an Application to Spain". European Economic Review 36, 1013-1053.

[13] Bertola, G. (1990), "Job Security, Employment and Wages". European Economic Review $34,851-879$.

[14] Bertola, G. (2004), "A Pure Theory of Job Security and Labor Income Risk". Review of Economic Studies 71, 43-61.

[15] Blanchard, O.J. and A. Landier (2002), "The Perverse Effects of Partial Labor Market Reform: Fixed Duration Contracts in France". Economic Journal 112, F214-244. 
[16] Boeri, T. (1999), "Enforcement of Job Security Regulations, On-the-Job Search and Unemployment Duration". European Economic Review 43, 65-89.

[17] Booth, A., M. Francesconi and J. Frank (2002), "Temporary Jobs: Stepping Stones or Dead Ends?". Economic Journal 112, F189-213.

[18] Cabrales, A. and H. Hopenhayn (1997), "Labor Market Flexibility and Aggregate Employment Volatility". Carnegie-Rochester Conference Series on Public Policy 46, 189-228.

[19] Cahuc, P. and F. Postel-Vinay (2002), "Temporary Jobs, Employment Protection and Labor Market Performance". Labour Economics 9, 63-91.

[20] de la Rica, S. (2004). "Wage Gaps Between Workers with Indefinite and Fixed-Term Contracts. The Impact of Firm and Occupational Segregation". Moneda y Crédito, 219, 43-69.

[21] Díaz-Moreno, C. and J.E. Galdón-Sánchez (1999), "How Important Is Firm Behavior to Understand Employment? Evidence from Spain". Investigaciones Económicas 23, 203-224.

[22] Dolado, J.J., C. García-Serrano and J.F. Jimeno (2002), "Drawing Lessons from the Boom of Temporary Jobs in Spain". Economic Journal 112, F270-295.

[23] European Commission (1996 and 1997), Labour Market Studies, Several Countries. European Communities, Luxembourg.

[24] Fogli, A. (2000), "Endogenous Labor Market Rigidities and Family Ties". Mimeo, New York University.

[25] Galdón-Sánchez, J.E. and M. Güell (2000): "Let's Go to Court! Firing Costs and Dismissal Conflicts". Princeton University IRS Working Paper 444.

[26] Goux, D., E. Maurin and M. Pauchet (2001), "Fixed-Term Contracts and the Dynamics of Labour Demand". European Economic Review, 45, 533-52.

[27] Güell, M. (2000a), "Fixed-Term Contracts and Unemployment: an Efficiency Wage Analysis". Princeton University IRS Working Paper 433.

[28] Güell, M. (2000b), "Fixed-Term Contracts and the Duration Distribution of Unemployment". Princeton University IRS Working Paper 443.

[29] Güell, M. and B. Petrongolo (2000), "Workers' Transitions from Temporary to Permanent Employment: The Spanish Case". LSE-CEP Discussion Paper 0438.

[30] Holmlund B. and D. Storrie (2002), "Temporary Work in Turbulent Times: The Swedish Experience". Economic Journal 112, F245-269.

[31] Hopenhayn, H. and R. Rogerson (1993), "Job Turnover and Policy Evaluation: A General Equilibrium Analysis". Journal of Political Economy 103, 915-938. 
[32] Jimeno, J.F. and L. Toharia (1993), "The Effects of Fixed-Term Employment on Wages: Theory and Evidence from Spain". Investigaciones Económicas 17, 475-494.

[33] Kramarz, F. and M.L. Michaud (2004), "The Shape of Hiring and Separation Costs", IZA Discussion Paper 1170.

[34] Lazear, E.P. (1990), "Job Security Provisions and Employment", Quarterly Journal of Economics 105, 699-726.

[35] Ljungqvist, L. (2002), "How Do Layoff Costs Affect Employment?". Economic Journal $112,829-853$.

[36] Moen, E.R. (1997), "Competitive Search Equilibrium". Journal of Political Economy $105,385-411$.

[37] Mortensen, D. and R. Wrigth (2002). "Competitive Pricing and Efficiency in Search Equilibrium". International Economic Review 43, 1-20.

[38] Nagypal, E. (2002), "The Cost of Employment Protection in the Presence of MatchSpecific Learning", Mimeo, Northwestern University.

[39] Nickell, S. (1997), "Unemployment and Labor Market Rigidities: Europe versus North America". Journal of Economic Perspectives 11, 55-74.

[40] OECD (1993, 1994), Employment Outlook. OECD, Paris.

[41] Osuna, V. (2005), "The Effects of Reducing Firing Costs in Spain: A Lost Opportunity?". Contributions to Macroeconomics 5, 1, Article 5.

[42] Petrongolo, B, and C.A. Pissarides, C.A. (2000), "Looking into the black box: A survey of the matching function". Journal of Economic Literature 39, 390-431.

[43] Pissarides, C.A. (2000), Equilibrium Unemployment Theory, second edition. MIT Press.

[44] Saint-Paul, G. (1996), Dual Labor Markets. A Macroeconomic Perspective. MIT Press, Cambridge, Massachusetts.

[45] Saint-Paul, G. (2002), "Employment Protection, Innovation and International Specialization", European Economic Review 46, 375-395.

[46] Veracierto, M. (2001), "Employment Flows, Capital Mobility, and Policy Analysis". International Economic Review 42, 571-596.

[47] Wasmer, E. (1999), "Competition for Jobs in a Growing Economy and the Emergence of Dualism in Employment". Economic Journal 109, 349-371. 
Table 1

Distribution of the share of temporary employment in total employment

\begin{tabular}{|c|c|c|c|c|c|c|c|c|c|c|c|c|}
\hline & 1985 & 1990 & 1991 & 1992 & 1993 & 1994 & 1995 & 1996 & 1997 & 1998 & 1999 & 2000 \\
\hline EU-15* & 9.0 & 10.2 & 10.4 & 10.9 & 10.6 & 11.0 & 11.5 & 11.8 & 12.2 & 12.8 & 13.2 & 13.4 \\
\hline Belgium & 6.9 & 5.3 & 5.1 & 4.9 & 5.1 & 5.1 & 5.3 & 5.9 & 6.3 & 7.8 & 10.3 & 9.0 \\
\hline Denmark & 12.3 & 10.8 & 11.9 & 11.0 & 10.7 & 12.0 & 12.1 & 11.2 & 11.1 & 10.1 & 10.2 & 10.2 \\
\hline Germany* & 10.0 & 10.5 & 10.1 & 10.5 & 10.3 & 10.3 & 10.4 & 11.1 & 11.7 & 12.3 & 13.1 & 12.7 \\
\hline Greece & 21.1 & 16.5 & 14.7 & 10.2 & 10.4 & 10.3 & 10.2 & 11.0 & 10.9 & 13.0 & $13.0^{(2)}$ & 13.1 \\
\hline Spain & 15.6 & 29.8 & 32.2 & 33.5 & 32.2 & 33.7 & 35.0 & 33.6 & 33.6 & 32.9 & 32.7 & 32.1 \\
\hline France & 4.7 & 10.5 & 10.2 & 10.5 & 10.9 & 11.0 & 12.3 & 12.6 & 13.1 & 13.9 & 14.0 & 15.0 \\
\hline Ireland & 7.3 & 8.5 & 8.3 & 8.7 & 9.4 & 9.5 & 10.2 & 9.2 & 9.4 & $9.4^{(1)}$ & $9.4^{(1)}$ & 4.6 \\
\hline Italy & 4.8 & 5.2 & 5.4 & 7.5 & 6.0 & 7.3 & 7.2 & 7.5 & 8.2 & 8.6 & 9.8 & 10.1 \\
\hline Luxembourg & 4.7 & 3.4 & 3.3 & 2.9 & 3.0 & 2.9 & .. & 2.6 & 2.1 & 2.9 & 3.4 & 3.4 \\
\hline Netherlands & 7.5 & 7.6 & 7.7 & 9.7 & 10.0 & 10.9 & 10.9 & 12.0 & 11.4 & 12.7 & 12.0 & 14.0 \\
\hline Austria & & & & & & & 6.0 & 8.0 & 7.8 & 7.8 & 7.5 & 7.9 \\
\hline Portugal & 14.4 & 18.3 & 16.4 & 11.0 & 9.8 & 9.4 & 10.0 & 10.6 & 12.2 & 17.3 & 18.6 & 20.4 \\
\hline Finland & 10.5 & 11.5 & 12.0 & 13.1 & 12.7 & 12.9 & 16.5 & 17.3 & 17.1 & 17.7 & 18.2 & 17.7 \\
\hline Sweden & 11.9 & 10.0 & 9.8 & 10.5 & 11.5 & 11.5 & 12.5 & 11.8 & 12.1 & 12.9 & 13.9 & 14.7 \\
\hline$U K$ & 7.0 & 5.2 & 5.3 & 5.5 & 5.9 & 6.5 & 7.0 & 7.1 & 7.4 & 7.1 & 6.8 & 6.7 \\
\hline
\end{tabular}

Source: European Commission. Employment in Europe (1985-1996) and Labour Force Survey (1997-2000).

* Since 1991, data on Germany and EU-15 include the new German Länder
(1) Ireland reports the 1997 value for 1998 and 1999.
(2) Greece reports the 1998 value for 1999. 


\section{Table 2}

\begin{tabular}{cll}
\hline Within-group regression of the share of temporary \\
\hline \multicolumn{3}{c}{ employment over the unemployment rate } \\
\hline Coefficient & 0.182 & -0.008 \\
p-value & 0.08 & 0.96 \\
& & \\
F test & 61.2 & 67.7 \\
p-value & 0.00 & 0.00 \\
\hline
\end{tabular}


Table 3: Benchmark Economy Parameterization Technology parameters

\begin{tabular}{lll}
\hline Relative productivity of new workers & $\lambda$ & 0.795 \\
Technological coefficient of labor & $\alpha$ & 0.6282 \\
Technological coefficient of capital & $\gamma$ & 0.2718 \\
Depreciation & $\delta$ & 0.12 \\
Productivity shocks' persistence & $\rho$ & 0.691 \\
Productivity shocks' S.D. & $\nu$ & 0.196 \\
Elasticity of probability of finding job & $\xi$ & 0.4 \\
Voluntary quits & $\omega$ & 0.0232 \\
Death probability & $\sigma$ & 0.022 \\
\hline \multicolumn{4}{c}{ Preference Parameters } \\
\hline Discount factor $\beta$ & 0.9795 \\
\hline \multicolumn{3}{c}{ Policy Parameters } \\
\hline Firing costs $\phi^{F}=\theta_{n}^{F} / w_{n}$ & 0.511 \\
Hiring costs (permanents) & $\phi^{P}=\theta_{n}^{H} / w_{n}$ & 0.098 \\
Hiring costs (fixed-term) & $\phi^{H}=\theta_{m}^{H} / w_{m}$ & 0.159 \\
\hline
\end{tabular}




\begin{tabular}{cccc}
\hline \multicolumn{4}{c}{ Table 4: Aggregate Quantities } \\
\hline & Benchmark & No Temporary & No Firing \\
Economy & Contracts & Costs \\
Output & 100 & 105.49 & 99.91 \\
Capital/Output Ratio & 100 & 95.81 & 101.59 \\
Aggregate Firing/Hiring Costs & 100 & 101.10 & 34.92 \\
Average Labor Productivity & 100 & 95.59 & 102.71 \\
Profits & 100 & 106.33 & 116.19 \\
\hline
\end{tabular}




\begin{tabular}{llll}
\hline \multicolumn{4}{c}{ Table 5: Prices } \\
\hline & Benchmark & No Temporary & No Firing \\
& Economy & Contracts & Costs \\
Interest Rate & $4 \%$ & $4.70 \%$ & $3.75 \%$ \\
Wage permanents & 100 & 92.48 & 103.43 \\
Wage temporaries & 88.94 & NA & NA \\
\hline
\end{tabular}




\begin{tabular}{cccc}
\hline \multicolumn{4}{c}{ Table 6: Labor Market } \\
\hline & Benchmark & No Temporary & No Firing \\
& Economy & Contracts & Costs \\
Employment Rate & $80.51 \%$ & $88.90 \%$ & $78.22 \%$ \\
Unemployment Rate & $19.49 \%$ & $11.10 \%$ & $21.78 \%$ \\
Permanents & $67.75 \%$ & $100 \%$ & $100 \%$ \\
Temporaries & $32.25 \%$ & $0 \%$ & $0 \%$ \\
Job Creation/Destruction Rate & $31.53 \%$ & $19.33 \%$ & $35.56 \%$ \\
New jobs that are permanent & $0.79 \% \square$ & $100 \% \square$ & $100 \%$ \\
\hline
\end{tabular}


Figure 1: Search Effort versus Assets

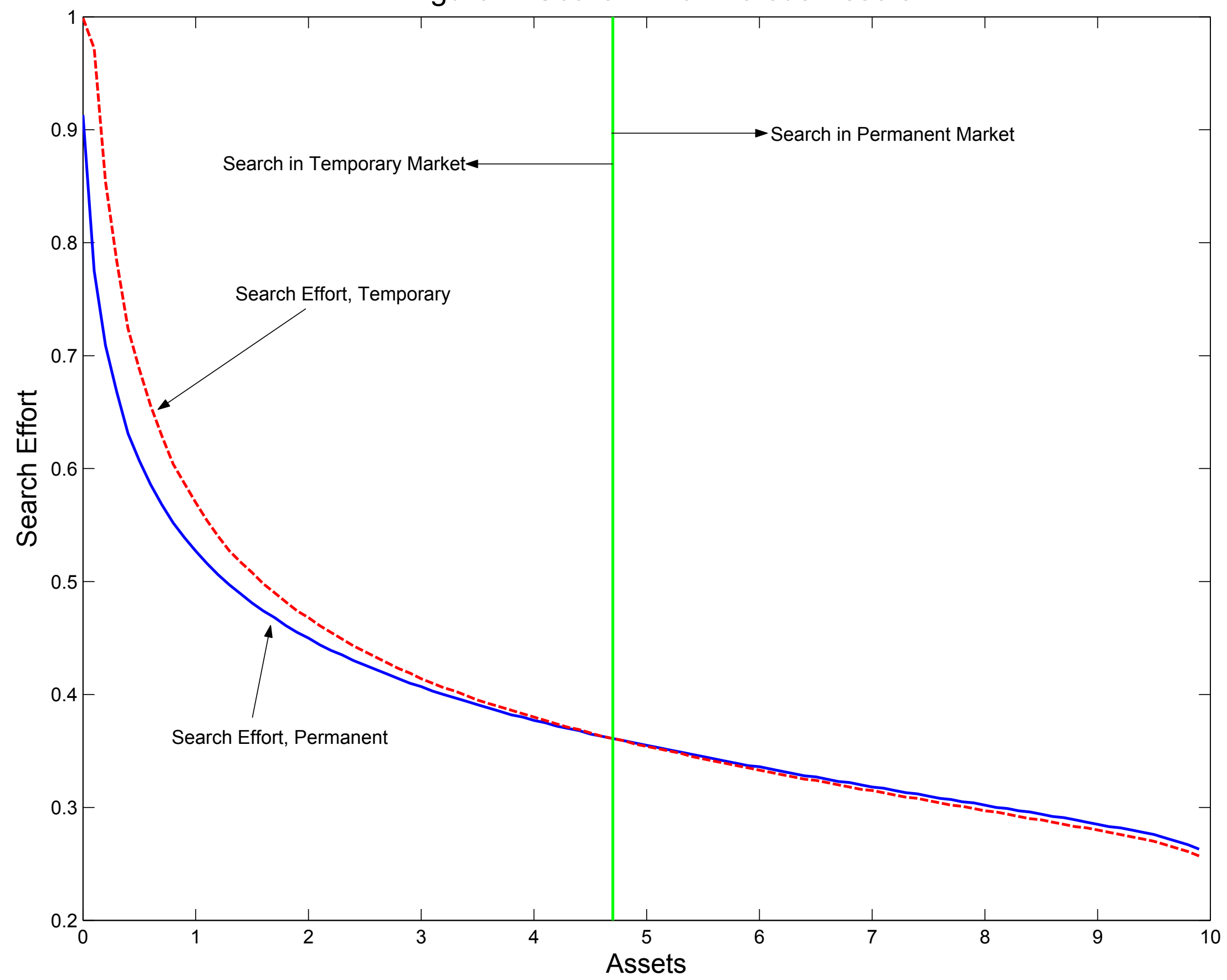


Figure 2: Search Effort versus Assets

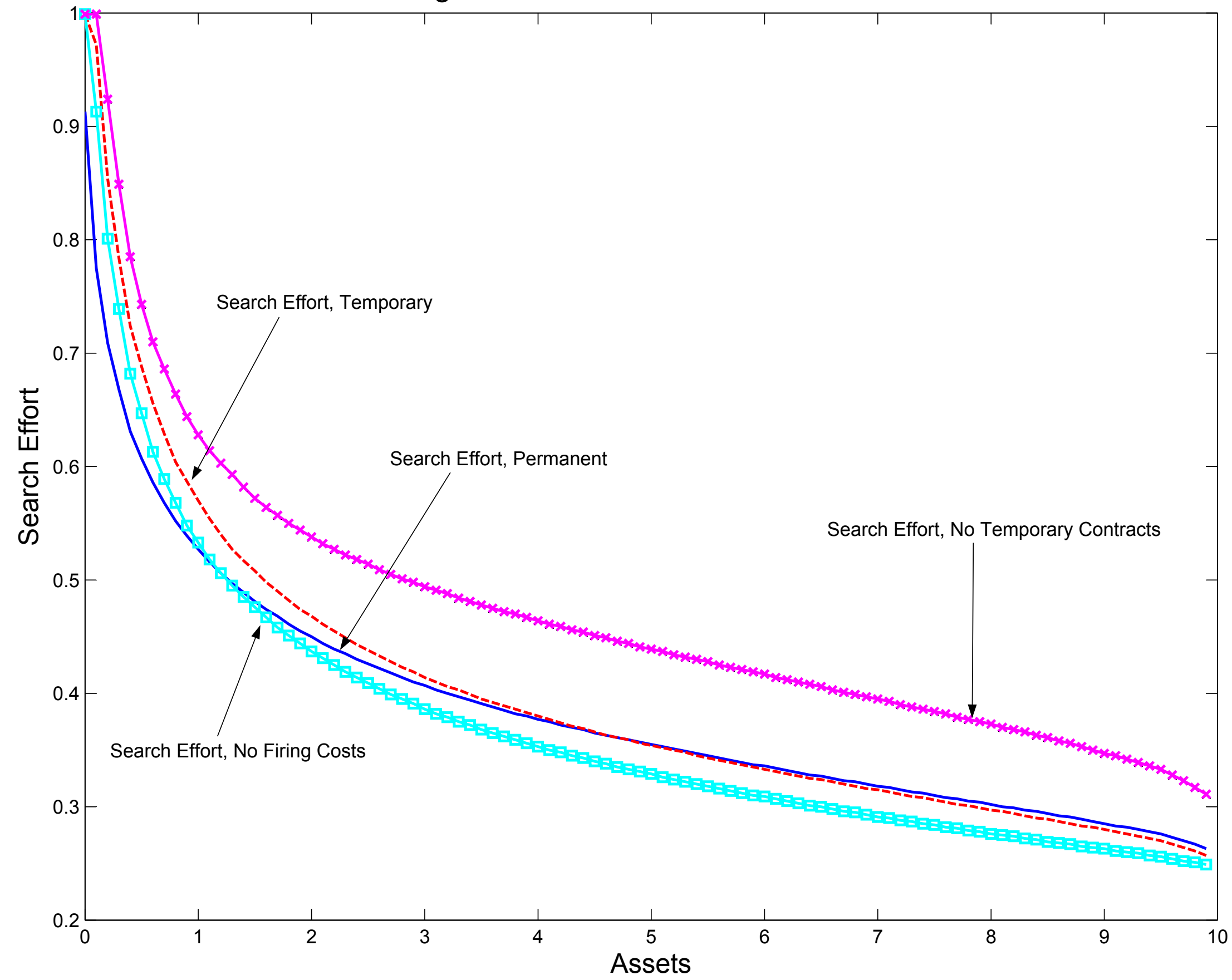

